\title{
Promising modulatory effects of autophagy on APP processing as a potential treatment for
} Alzheimer's disease

Md. Ataur Rahman ${ }^{1,} 2^{*}$, Md Saidur Rahman ${ }^{3}$, MD. Hasanur Rahman ${ }^{4}$, Mohammad Rasheduzzaman ${ }^{5}$, ANM Mamun-Or-Rashid ${ }^{6}$, Md Jamal Uddin ${ }^{7,8}$, Md Rezanur Rahman ${ }^{9}$, Hongik Hwang ${ }^{1}$, Myung-Geol Pang ${ }^{3}$, and Hyewhon Rhim ${ }^{1,10 *}$

${ }^{1}$ Center for Neuroscience, Brain Science Institute, Korea Institute of Science and Technology (KIST), Seoul 02792, Republic of Korea.

${ }^{2}$ Global Biotechnology \& Biomedical Research Network (GBBRN), Department of Biotechnology and Genetic Engineering, Faculty of Biological Sciences, Islamic University, Kushtia 7003, Bangladesh.

${ }^{3}$ Department of Animal Science \& Technology and BET Research Institute, Chung-Ang University, Anseong 456-756, Republic of Korea.

${ }^{4}$ Department of Biotechnology and Genetic Engineering, Bangabandhu Sheikh Mujibur Rahman Science and Technology University, Gopalgonj-8100, Bangladesh.

${ }^{5}$ School of Biomedical Sciences, Institute of Health and Biomedical Innovation, Translational Research Institute, Queensland University of Technology, Brisbane, QLD 4059, Australia.

${ }^{6}$ Anti-Aging Medical Research Center and Glycation Stress Research Center, Graduate School of Life and Medical Sciences, Doshisha University, Kyoto, Japan.

${ }^{7}$ Graduate School of Pharmaceutical Sciences, College of Pharmacy, Ewha Womans University, Seoul 03760, Republic of Korea.

${ }^{8}$ ABEx Bio-Research Center, East Azampur, Dhaka-1230, Bangladesh.

${ }^{9}$ Department of Biochemistry and Biotechnology, School of Biomedical Science, Khwaja Yunus Ali University, Sirajgonj 6751, Bangladesh.

${ }^{10}$ Division of Bio-Medical Science and Technology, KIST School, Korea University of Science and Technology (UST), Seoul 02792, Republic of Korea.

*Correspondence address to: Center for Neuroscience, Brain Science Institute, Korea Institute of Science and Technology (KIST), 5 Hwarang-ro 14-gil, Seongbuk-gu, Seoul 02792, Republic of Korea. Tel.: +82-2-958-5923, Fax: +82-2- 958-6937. Md. Ataur Rahman, E-mail:

ataur1981rahman@hotmail.com; Hyewhon Rhim, E-mail: $\underline{\text { hrhim@kist.re.kr }}$ 


\begin{abstract}
Autophagy refers to the degradation of cytoplasmic constituents by a lysosomal-mediated pathway, which plays a critical role in maintaining cellular homeostasis. Importantly, dysregulation of autophagy has been implicated in multiple neurodegenerative disorders. Previous studies reported that autophagy affects the processing of amyloid precursor protein (APP), thus stimulating $\beta$ amyloid $(\mathrm{A} \beta)$ production in Alzheimer's disease (AD) eventually. Although the mechanism of autophagy modulation on APP processing and its pathogenesis has not yet been fully elucidated at the molecular level, but modulation of autophagy has received considerable attention as a promising approach for the treatment of $\mathrm{AD}$. In the early stage of $\mathrm{AD}, \mathrm{A} \beta$ may prompt autophagy to facilitate its removal via mTOR-independent as well as-dependent pathways. However, a recent study proposed that autophagy processes are not properly regulated as AD continues to progress, and consequently, the production of $\mathrm{A} \beta$ tends to accumulate rapidly. Meanwhile, a number of autophagy-related genes (Atg) as well as APP genes are also thought to influence the development of $\mathrm{AD}$, which may serve as a bi-directional link to autophagy and AD pathology. In this review, we summarized current observations related to autophagy regulation and APP processing, focusing on their dynamic modifications associated with the progression of AD. Recent findings together highlight the essential role of autophagy in the removal and clearance of APP and A $\beta$ deposition in the pathological condition of AD.
\end{abstract}

Keywords: Autophagy; Amyloid precursor protein (APP); $\beta$-amyloid (A $\beta$ ); mTOR; Alzheimer's disease (AD). 


\section{INTRODUCTION}

Amyloid precursor protein (APP), a transmembrane glycoprotein (type-I), is a key molecular driver for Alzheimer's disease (AD) pathogenesis. An extracellular domain and a small cytosolic domain present in APP are generally accepted to be responsible for AD progression [1]. APP is ubiquitously present in the brain, and is involved in building synaptic network as well as regulating neurogenesis [2]. In addition, APP has a modulatory effect in cell surface receptors and axonal transport. However, the exact functionality of the APP still remain elusive [3]. In general, upon its synthesis on the endoplasmic reticulum, phosphorylation and glycosylation of APP take place and APP is finally transported into the Golgi apparatus. Additional processing of APP is also observed in the trans-Golgi-network (TGN), and the highest concentrations of APP are found in TGN under normal physiological conditions. Cleavage of APP by $\alpha$-secretase produces a soluble molecule, sAPP $\alpha$, within the A $\beta$ domain [4], and APP goes inside the cargo by the process known as the endosomal/lysosomal degradation pathway. Lysosomal degradation is a clearance mechanism required to maintain a healthy state and to prevent the accumulation of undesirable cellular wastes materials. The generated peptide serves an important role in synaptic plasticity and neuronal survival in the healthy state [5]. However, the toxic amyloidogenic peptide is produced due to the mutations of genes encoding APP, presenilin-1 and presenilin-2, and the excessive cleavage of APP through $\beta$-secretase (BACE-1) and $\gamma$-secretase in place of $\alpha$-secretase led to unwanted assembly and accretion of irregular $A \beta$ peptides. The diffusible oligomers and insoluble senile plaque are formed due to abnormal presentation of $\mathrm{A} \beta$ peptides, thereby resulting in higher neurotoxicity. Moreover, a fibrillary plaque is found in the intracellular space due to the aggregation of abnormal $A \beta$ oligomers [6]. Hyperphosphorylation of tau, the most common form of $\mathrm{AD}$, is interrelated to its aggregation as well as the formation of neurofibrillary tangles (NFTs) and is considered as pathologically condition of AD [7]. Intracellularly, NFTs are formed which contain a microtubule binding protein known as phosphorylated tau [8]. However, genetic mutations affect the levels of A $\beta$-peptide, for example Presenilin 1 (PSEN1), Presenilin 2 (PSEN2), and APP which cause AD pathogenesis [9]. Collectively, the neurotoxic effect of NFTs and A $\beta$ associated with the excessive accumulation of extracellular plaque in brain is a hallmark of AD pathogenesis [10]. 
Autophagy provides a widespread role in both physiological and multiple pathological conditions, including cancer and neuronal disorder [11], and has gained extensive linkage to the AD pathogenesis [12]. Autophagy, a self-digesting mechanism, is an intracellular cleansing process mediated by the removal of malformed proteins and damaged cellular organelles to membranebound vesicles known as autophagosome [11]. These autophagosomes subsequently fuse with the lysosome to form autophagolysosome that allows the degradation of its cargo, and acid hydrolysis mediates the lysosomal degradation of dysfunctional materials within the cell [13]. Autophagy is a complex and tightly regulated enzymatic process which is largely classified into two categories: mammalian target of rapamycin (mTOR)-independent and -dependent pathway. A defect in the autophagy lysosomal pathway harnessing pathological amyloids induces the formation of toxic A $\beta$ aggregates, which causes cellular apoptosis as well as tissue and organ damages, culminating into clinical symptoms. In the beginning of $\mathrm{AD}$, existence of $\mathrm{A} \beta$ may prompt autophagy to accelerate their removal process by employing both mTOR-independent and -dependent pathway. Progressi on of AD terminates the regular autophagy pathway, resulting in the continuous generation of $\mathrm{A} \beta$, which exaggerates both autophagy malfunction and $\mathrm{AD}$ [14]. In addition, both oligonucleotides and proteins, such as miRNAs, transcription factors EB (TFEB), presenilin, Nrf2, and Beclin-1 are simultaneously convoluted in the regulation of autophagy, which are meticulously interrelated to the pathogenesis of $\mathrm{AD}$ [15]. Therefore, it is evident that the regulation of autophagy is crucial for APP cleansing and the elimination of AD pathogenesis. Abnormal autophagy is associated with $\mathrm{AD}$ pathogenesis; therefore, targeting autophagy may have a profound role in $\mathrm{AD}$ management [16].

\section{AUTOPHAGIC PATHWAY}

The autophagy pathway is initiated with the generation of the phagophore and ends the clearance of the autophagosome. Degradation of autophagosome mediates that recycling of the cargo [17]. The autophagy related gene Atg12-Atg5-Atg16 complex controls the autophagosome formation and microtubule-associated protein light chain 3 (LC3-I)-phospholipid conjugates (LC3-II). Both of LC3-I and II are used as a marker for double-membrane vesicle autophagosome. Furthermore, p62 is a marker for lysosomal degradation, which indicates autophagosome produced by 
interaction with lysosome degrades its cargo. This state is known as the activation of the autophagic flux [18].

A starving condition in a cell initiates autophagy response, and a double-membraned structure, known as autophagosome, is produced by the sequestration of the cytoplasmic materials. Autophagosome fuses with lysosome, and acid hydrolysis degrades the cargo, which contributes to the mitochondrial quality control and cellular homeostasis [19]. Autophagy can be portioned into the following steps: the formation of isolated membrane (nucleation), membrane elongation, autophagosome maturation, docking and fusion between autophagosome with the endosome and finally the lysosome, and degradation of the internal materials inside the autolysosome [17] (Figure 1). Autophagy is controlled by numerous growth factors as well as nutrient signaling, such as mTOR complex 1 (mTORC1) and class I PI3K/Akt signaling pathway. Dysregulation of autophagy deposits unwanted debris within a cell rather than recycling; therefore, inhibition of autophagy is implicated in multiple pathophysiological processes, including neurodegenerative diseases like AD [11].

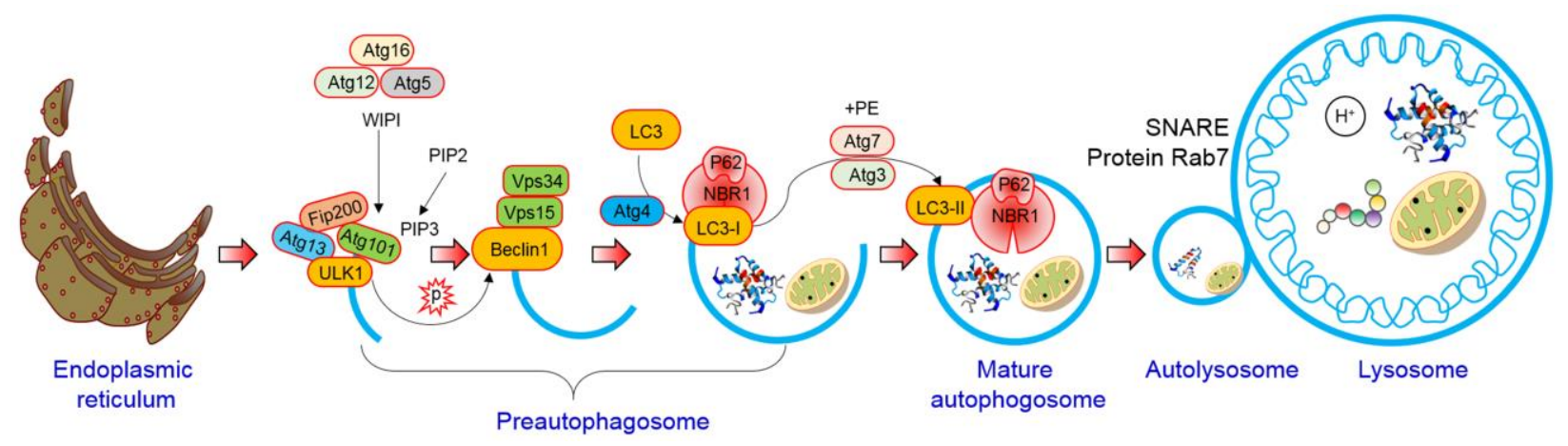

Figure 1: Schematic diagram of different phases of autophagy. Autophagy is initiated by inactivation of mTOR pathways and numerous autophagy related proteins. Pre-autophagosome synthesis comprises with coupling of LC3 in association with ULK1 and Vps34 protein. Autophagosome membrane along with formation of double membrane vesicles are sequestered material of cytoplasm which form mature autophagosome. Finally, fusion of mature autophagosomes and lysosomes discharge the products into the cytoplasm which may further used as nutrients. 


\subsection{Autophagy pathway: mTOR-dependent}

Mammalian target of rapamycin (mTOR) is an essential serine-threonine protein kinase, comprising mTOR complex 1 (mTORC1) as well as mTOR complex 2 (mTORC2) [20]. mTOR is known as a classical regulator of autophagy and controls vital cellular functions, such as protein translation and cell growth $[21,22]$. The mTOR activity is closely associated with numerous factors, including chronic stress, starvation, and glucocorticoids. During starvation, mTORC1 activity is down-regulated, thereby initiating autophagy to recycle intracellular constituents and thus to generate a source of energy. Phosphoinositide 3-kinases (PI3K) as well as protein kinase B (Akt/PKB) are dual upstream mTOR molecules [20]. These two molecules interact with mTOR and modulate the PI3K/Akt/mTOR pathway that controls autophagy. However, blockage as well as inhibition of any molecules of this pathway triggers autophagy, thereby augmenting the clearance or removal of $\mathrm{A} \beta$ in $\mathrm{AD}$ [20]. Previous studies have been shown that the inhibition of mTORC1 during starvation or its pharmacological blockade with rapamycin, CCI-779, Torin1 or PP242 stimulates autophagy [23,24].

Furthermore, adenosine 5'-monophosphate-activated protein kinase (AMPK) elicits autophagy [22]. AMPK is an upstream regulator of mTOR. However, peroxisome proliferator-activated receptors- $\gamma$ (PPAR $\gamma)$ and mTOR organized PPAR $\gamma /$ AMPK/mTOR also regulate the autophagy. In addition, dihydroceramide desaturase (Des1 and Des2) are the enzymes that catalyze the synthesis of dihydroceramide into ceramide, which can trigger the levels of mTORC1 and inhibition of autophagy (Figure 2). The findings from a study suggested that inhibiting Des1 activity might modulate autophagy and mTORC1 activity in neurons, thereby suppressing amyloid secretion in AD [25]. In addition, the transient receptor potential mucolipin-1 (TRPML1) is extensively articulated in cell lysosomes, which also serves as an autophagy regulator. Lacking the activity of TRPLM1 PPAR $\gamma / A M P K$ signaling pathway block mTOR signaling, triggering the accumulation of degraded cellular components via the inhibition of autophagy flux. A study using transgenic mice revealed that TRPML1 is a precursor for the progression of AD due to the blocking of autophagy machinery [26]. Besides, DNA damage, oxidative stress, hypoxia, and metabolic stress generate reactive oxygen species (ROS) which modulate autophagy via the Akt/mTOR pathway $[27,28]$. 


\subsection{Autophagic pathway: mTOR-independent}

An increase in AMPK-mediated phosphorylation activates autophagy machinery. $\mathrm{Ca}^{2+}$-dependent protein kinase $\beta(\mathrm{CaMKK} \beta)$ is an upstream controller of AMPK, and the influx of $\mathrm{Ca}^{2+}$ through TRPM7 maintains basal autophagy via the CaMKK $\beta / A M P K$ pathway. The aggregation of $A \beta$ interferes with the homeostasis of $\mathrm{Ca}^{2+}$ levels that causes mitochondrial dysfunction, which is closely connected to the AD pathogenesis [29]. Generally, AMPK-mediated phosphorylation occurs in the serine-317/777 sites of autophagy initiation kinase, ULK1. In addition, AMPK, an upstream signaling molecule of Beclin-1, is related with pre-autophagosmal complex initiation and AMPK directly phosphorylates the serine-91/94 sites of Beclin-1, thereby initiating autophagy (Figure 2). Inflammatory response activates the microglia that increase the transportation of p-tau in neurons and assist the degradation of p-tau in lysosomes. This course of action increases autophagic flux in microglia and assists the clearance of cellular debris in a regular manner. ROS production by mitochondria causes an oxidative damage to mitochondrial proteins and triggers autophagy-mediated cell death via mTOR independent manner [30].

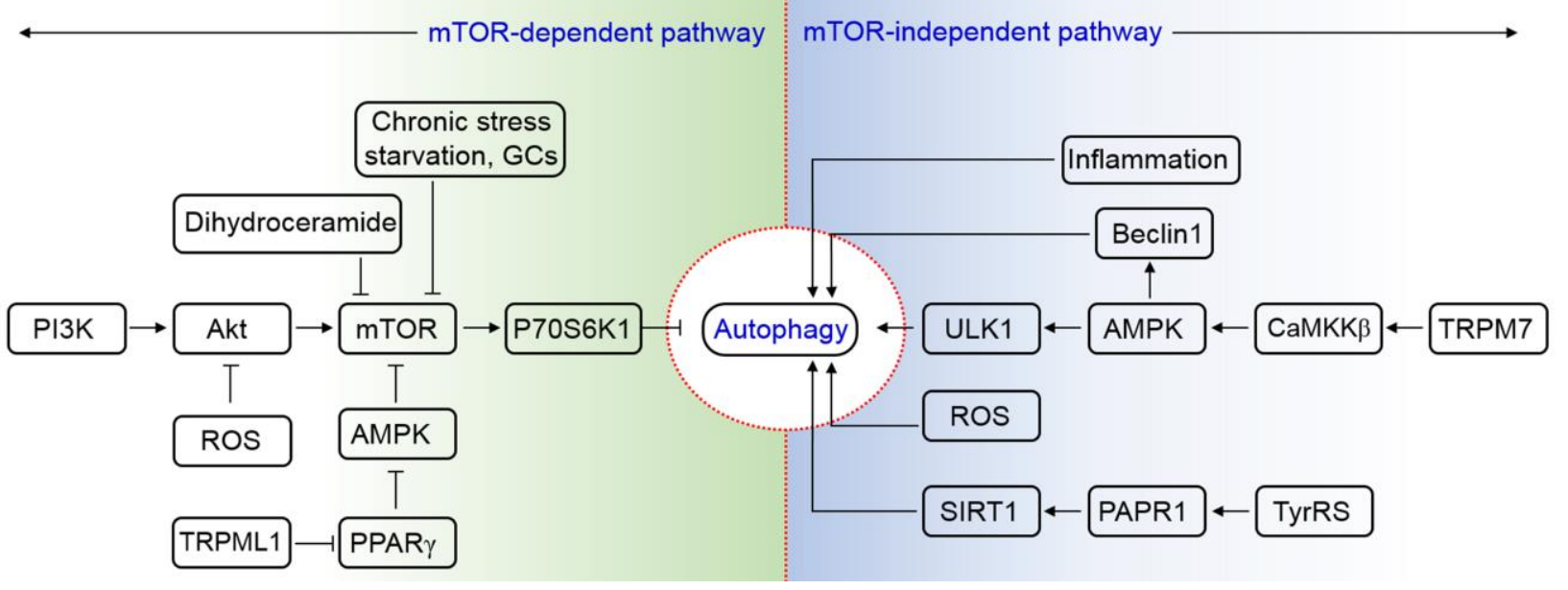

Figure 2: Autophagy regulates by mTOR signaling pathway. mTOR-dependent pathway as well as mTOR-independent pathway can be regulated the overall autophagy signaling. mTOR phosphorylation can lead to ribosomal P70S6K1 phosphorylate which is a mTOR substrate protein, therefore preventing autophagy initiation. Another physiological condition, autophagic pathway can additionally be stimulated over some other elements for example starvation, chronic stress, as well as GCs through mTOR inhibition. Furthermore, TRPML1/PPAR $\gamma / A M P K / m T O R$ and 
$\mathrm{PI} 3 \mathrm{~K} / \mathrm{Akt} / \mathrm{mTOR}$ are positive and negative autophagy regulator respectively, stimulation as well as prevention of these pathways may trigger autophagy. Also, dihydroceramide is a controller of mTOR-mediated autophagy induction. However, ROS stimulates autophagy via mTOR-dependent as well as mTOR-independent pathways. Besides, inflammatory stimulation of microglia similarly acting a role autophagy in initiating in some condition. TRPM7, CaMKK $\beta$, AMPK as well as TyrRS, PARP1, SIRT1 are most important positive pathways in autophagy regulation of mTORindependent pathways.

\section{NEURONAL ROLES OF APP}

Although $\mathrm{A} \beta$ plays the fundamental role in the pathogenesis of $\mathrm{AD}$, the evolutionary preservation of APP and the existence of APP isoforms that lack the APP gene sequence indicate that amyloid formation is not an intended physiological function of this family of proteins under normal circumstance. Current amassed evidence has shown that APP is vital for the generation, differentiation, and migration of neurons [31]. In dominant expression neuronal cells could rescue this phenotype significantly. In addition, APP also plays a significant role in Drosophila melanogaster, and the suppression of APPL gene causes an alteration of chemotactic behavior [32]. Interestingly, high levels of APPL are associated with the neuronal regeneration in the brain injury model of Drosophila increased mortality. APPL is positively correlated with the increased protrusions of dendritic neurites, and the potential role of APP in axonal growth after a traumatic brain injury was reported previously [33]. Moreover, overexpression of APP promotes synaptic differentiation, and APPL mutants reduce the number of synaptic lobes in the Drosophila neuromuscular junction [34].

APP is omnipresent in mammalian cells and shown to have a multifunctional role in cellular functions, such as cell adhesion, differentiation of neuronal cells, nerve migration, synapse formation, and neurite growth. APP immunoreactivity was reported to increase after a brain injury in mice, which is consistent with a traumatic injury of the brain. APP-deficient mice showed weight loss, balance and muscle weakness, impaired behavior and long-term potentiation [35]. Evidence from other animal models of APP deficiency has demonstrated the potential role of APP in the generation, differentiation, and migration of neurons. The potentially important role of APP as part of a complex mechanism involved in several neurological functions, such as nerve 
development [36]. Growing evidence suggests that soluble sAPP $\alpha$ plays a neuroprotective role and functions similar to growth factors, and it has been shown that the APP intracellular domain (AICD) interacts with numerous proteins involved in the regulation of transcription and axonal transport [37].

\section{APP PROTEOLYTIC PROCESSING IN ALZHEIMER'S DISEASE}

APP is proteolytically cleaved into several fragments during intracellular transport, and these metabolites of APP mediate multiple cellular functions, some of which are harmful. Thus, the net effect of the full-length APP on the activity of cells may be due to the combination of different metabolite roles that mainly depend on the percentage of each APP metabolite level. APP may undergo non-amyloidogenic or amyloidogenic excision by several secretases [38,39]. APP amyloidogenic processing, which is first mediated by $\beta$-secretase, leads to the production of a large APP (sAPP $\beta$ ) and AICD containing a carboxy-terminal fragment (CTF99) [39]. In the brain, $\beta$ site cleavage enzyme of APP (BACE1) is considered as a primary $\beta$ secretase [40]. APP also undergoes proteolytic processing by an $\gamma$-secretase complex containing presenilin, which is known as a non-amyloidogenic pathway [41]. In this process, $\mathrm{A} \beta$ sequence is cleaved from inside, resulting in the formation of $\mathrm{A} \beta$ [42]. The non-amyloidogenic processing produces a carboxyterminal fragment $(\mathrm{CTF} 83)$ and a soluble fragment $(\mathrm{sAPP} \alpha)$ which is thought to play a neuroprotective role in contrast to A $\beta$ [43]. The CTF83 and CTF99 fragments are consecutively cut in the transmembrane domain by the action of $\gamma$-secretase, producing AICD and A $\beta$, respectively $[44,45]$. Induced levels of $\beta$-secretase were reported to increase the level of CTF99 and $\mathrm{A} \beta$ as well as the reduction in CTF83 and AICD levels in vitro. In contrast, higher levels of $\alpha$-secretase drive to increase AICD43 generation [46]. The details of APP processing by the amyloidogenic and non-amyloidogenic process are demonstrated in Figure 3. Collectively, the cleavage of APP by $\alpha$-secretase and $\beta$-secretase may have different effects on the subsequent release of AICD [40]. 


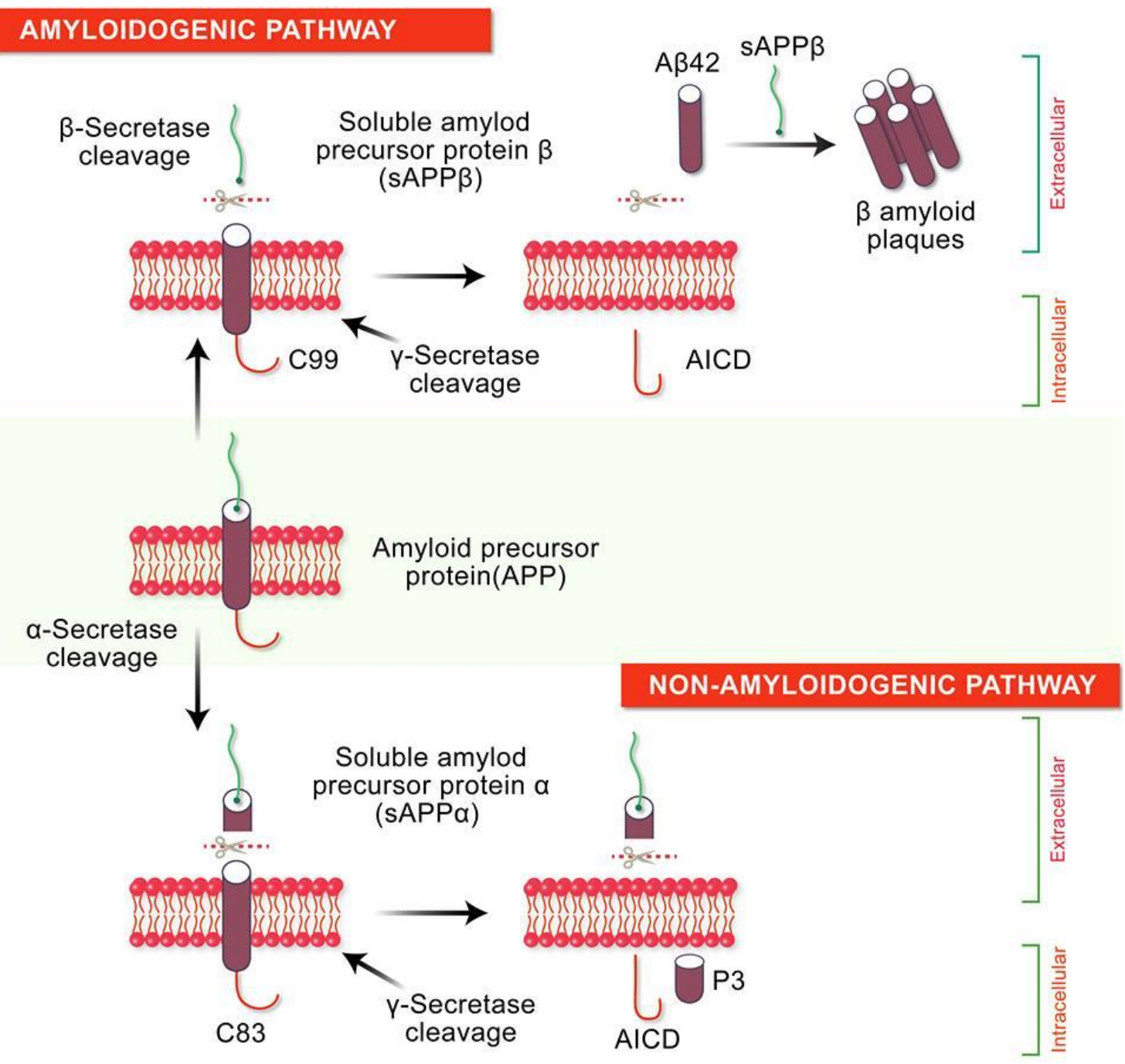

Figure 3: The non-amyloidogenic pathway cleavages APP through $\alpha$-secretase to form two fragments, intracellular C-terminal fragment, C83, and soluble amyloid precursor protein $\alpha, \operatorname{sAPP} \alpha$, extracellular fragment. Cleavage of C83 fragment via $\gamma$-secretase yields a P3 peptide short fragment and APP intracellular domain (AICD) fragment. The amyloidogenic stores pathway neurotoxic A $\beta$. Extracellular SAPP $\beta$ releases by $\beta$-Secretase in addition to large $\mathrm{N}$-terminal soluble amyloid precursor protein C99 fragment. C99 fragment Cleavage by $\gamma$-secretase produces the A $\beta$ peptide.

\section{PATHOGENESIS OF APP}

Under a regular condition, APP is cleaved inside the A $\beta$ domain by the action of $\alpha$-secretase [1]. The peptides produced are non-amyloidogenic and can have an advantageous consequence on 
synaptic flexibility as well as neuronal survival at the physiological level. In contrast, mutations in the APP, presenilin-1 and presenilin-2 genes were reported to facilitate the excision of APP by the action of $\beta$-secretase (BACE-1) and $\gamma$-secretase in place of $\alpha$-secretase, which resulted in excessive generation and accumulation of $A \beta$ peptide [47]. The $A \beta$ peptides exhibit high neurotoxicity by forming insoluble senile plaque and diffusible oligomers. The $A \beta$ oligomers are also combined to form a fibrillar structure in the intracellular space that accumulates and deposits on the plagues. In addition, $\mathrm{A} \beta$ oligomers enhance phosphorylation and aggregation of tau proteins, although its mechanism is still unknown at the molecular level. Evidence also suggests that the suppression of the tau protein decreases the production of $A \beta$ and inhibits the toxicity induced by the feedback mechanism [10]. On the other hand, phosphorylated tau causes the destabilization of the microtubules, the degeneration of the cell membrane, and the intracellular aggregation of NFT, which eventually leads to cell death [8]. In addition, it has been also proposed that $A \beta$ accumulation and aggregation of p-tau cause ER stress and contribute to synaptic dysfunction as well as neurodegeneration in $\mathrm{AD}$ [10]. The ER compartment regulates protein folding, modification, and quality control, and mild stress in ER causes the denaturation of misfolded and aggregated proteins in the ER lumen and prompts an unfolded protein response (UPR) to restore the homeostasis of proteins. However, excessive stress promotes UPR reports to proapoptotic programs and causes cell death [48] (Figure 4). 


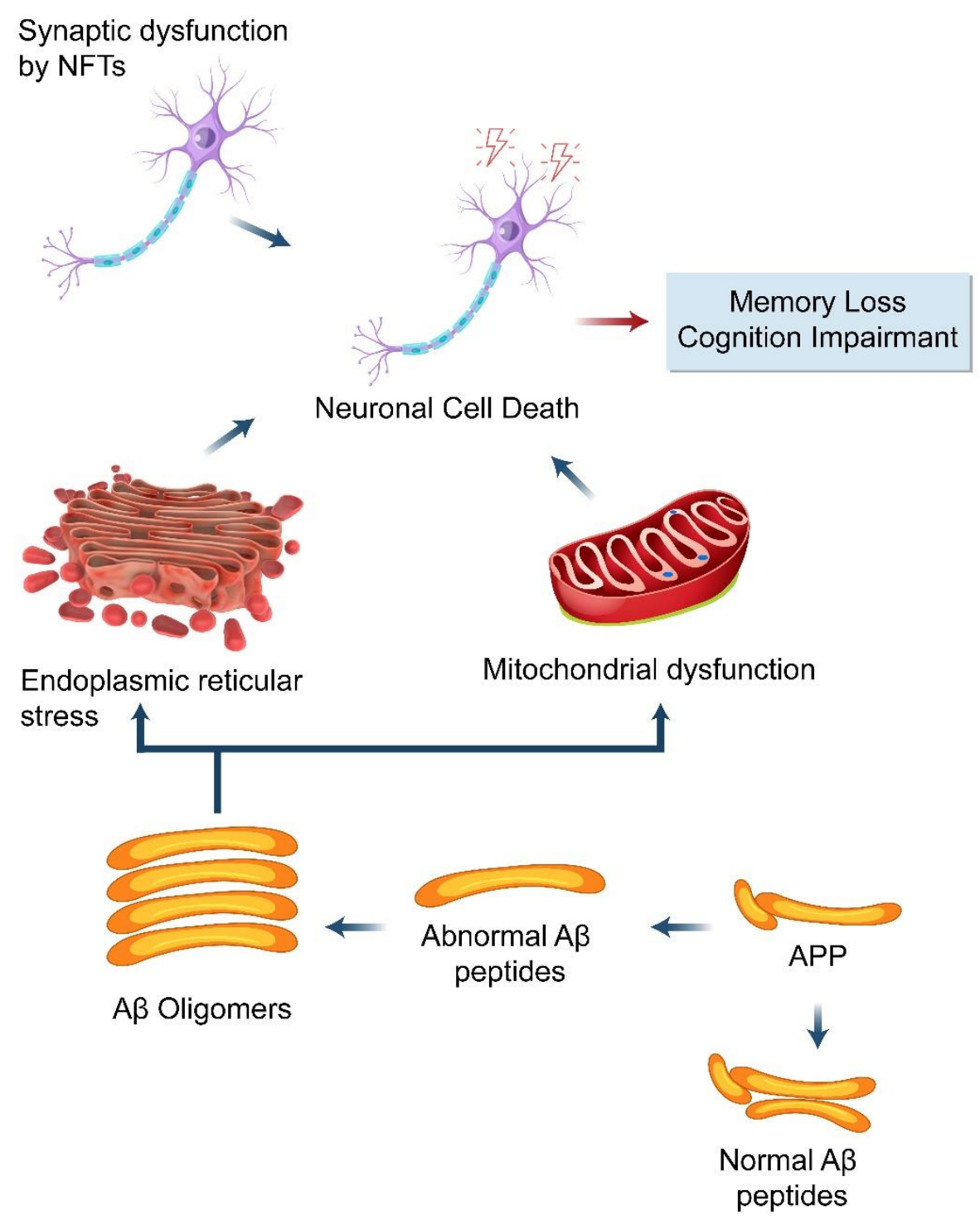

Figure 4: Schematic representing AD pathogenesis modulation by APP. AD pathogenesis initiates from accumulation of abnormal A $\beta$ peptides derived from APP proteolytic cleavage through $\gamma$-secretase and $\beta$-secretase. A $\beta$ oligomers stimulates ER stress and trigger mitochondrial injury which lead to initiate neuronal death in addition to cognition impairment during $\mathrm{AD}$ progression. In addition, synaptic dysfunction is also initiated by phosphorylation of tau which lead to form NFTs which cause the loss of neurons in AD. 


\section{AMYLOID PRECURSOR PROTEIN (APP) PROCESSING IN AUTOPHAGIC PATHWAY}

Autophagy is a cellular process that removes the unnecessary substances from the cell by acid hydrolases within the lysosomes [11]. Increasing evidences show that autophagy process is impaired in various neurodegenerative diseases, including AD. Aging process is also involved in the interruption of autophagy process which ultimately leads to AD pathogenesis [49]. The activation of autophagy is associated with the reduction of $A \beta$ deposition and improves memory deficits in AD mice. Autophagy is a main signaling for altering APP as well as intracellular A $\beta$ peptides production. Autophagy vacuoles (AVs) contain immunoreactive $A \beta$ and its precursor proteins in AD models [50]. In addition, the levels of APP in AVs are constant, implying that the cleavage of APP arises in the AVs [51]. This is supported by the data that those AVs contain secretase accountable for producing CTF [16]. In addition, AV fractions encompass notable levels of presenilin-1 in addition to nicastrin, demonstrating that AVs are the slot for abnormal APP cleavage [50] (Figure 5).

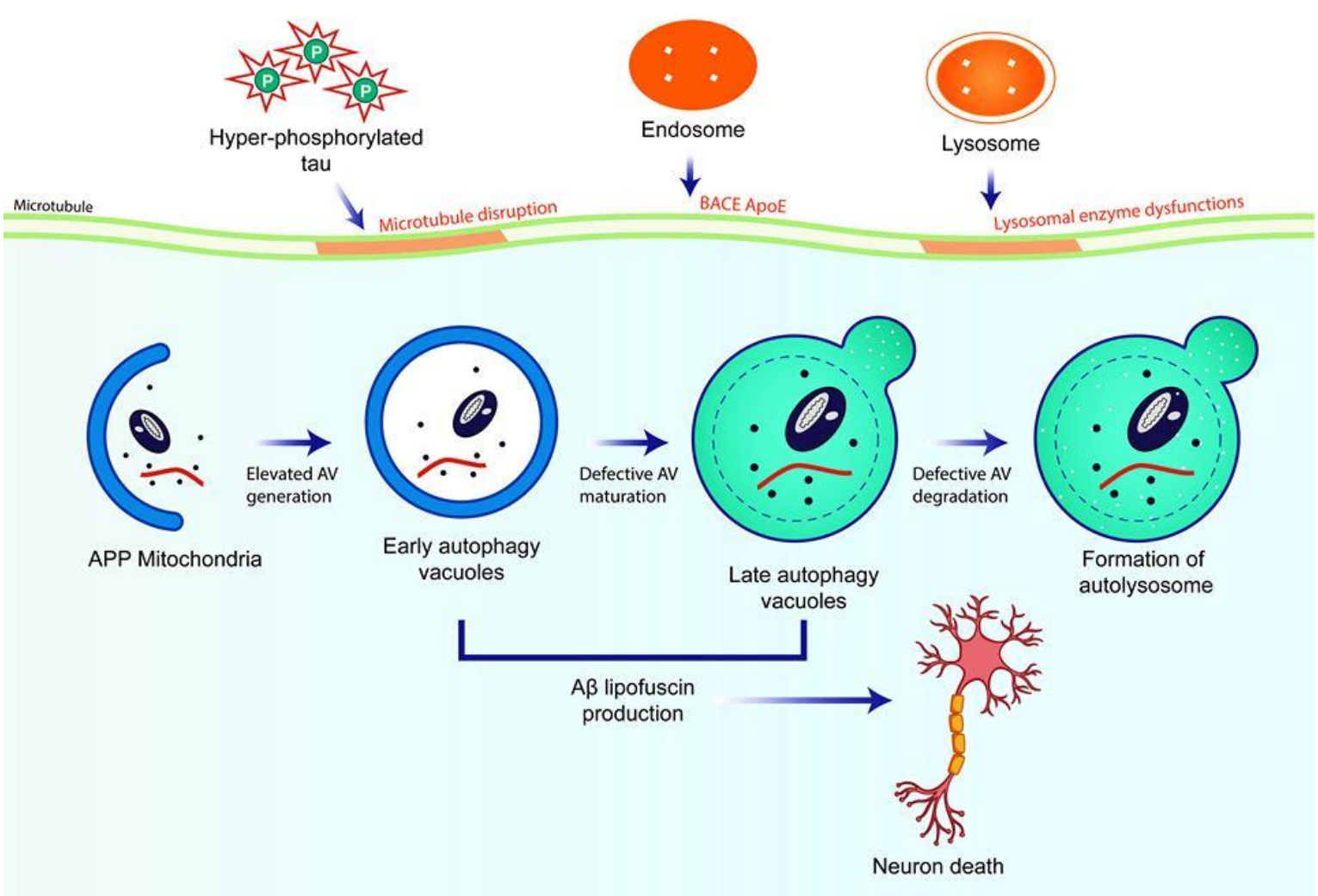


Figure 5: Related molecules such as ApoE, BACE, and APP are dealing with autophagy in initial period of AD, autophagy vacuoles (AVs) are augmented via the stress of mutant APP which ultimately damaged mitochondria. During late stage of $\mathrm{AD}$, maturation as well as degradation of autophagosomes are blocked as a result of disruption of microtubule affected via hyperphosphorylation of tau. Tau hyperphosphorylation may effect on microtubule assembly inhibition and could be disrupted the preassembled microtubules in vitro [52]. Eventually, dysfunction of lysosome enzyme interferes autophagosome-lysosome fusion in AD. Entirely these defects of autophagy contribute to AVs accumulation along with AD-related others molecule which increases the intracellular $\mathrm{A} \beta$ deposition as well as lipofuscin causing neuronal cell degeneration and death.

\subsection{Autophagy and A $\beta$ processing}

APP is cleaved by $\beta$-secretase (BACE1) and $\gamma$-secretase to yield A $\beta[40,47]$. Acceleration of AD progression was observed when there was an enhanced activities of BACE1 as well as $\gamma$-secretase, which increases APP processing and the formation of A $\beta$ [53]. Autophagy exhibits a critical role in the processing of APP [54]. In animal model of AD, triggering of Atg5-dependent autophagy stimulates early degradation of APP, and thus, inhibits A $\beta$ accumulation [55]. Sirtuin1 (SIRT1), a positive regulator of autophagy, increases the expressions of Atg5, beclin-1, as well as LC3-II and accelerates clearance of $A \beta$ [56]. Inhibition of mTOR stimulates autophagy and decreases the levels of BACE1 expression in an APP/PS1 transgenic mouse model of AD [57]. In addition, PPAR $\alpha$-mediated activation of autophagy facilitated the clearance of APP and decreased A $\beta$ pathology in APP/PS1 mice [58]. Treatment of PPAR $\alpha$ agonists also decreased A $\beta$ levels in the hippocampus and cortex, and improved autophagosome biogenesis. These observations together suggest that PPAR $\alpha$ is a critical player for autophagy involved in the A $\beta$ processing [59]. The mutant APP was reported to impair energy metabolism in mitochondria in AD neurons. In addition, dysfunction of autophagy activates $\gamma$-secretase, and stimulates APP cleavage leading to the formation of $A \beta$. 3-Methyladenine (3-MA), an autophagy inhibitor, enhances $\gamma$-secretase to boost its activity and stimulate $A \beta$ production [60]. It is also reported that the unfamiliar autophagy activate APP cleavage which leads to the production of $A \beta$. All of these evidences indicate that APP is an autophagy substrate in the early stage of A $\beta$ production [50], and therefore, maintaining a regular function of autophagy is important for the removal and clearance of APP [61]. Still now, 
however, the molecular mechanism of how APP serves as a substrate for autophagy remains unclear.

\subsection{Dysfunctional autophagy and $A \beta$ processing}

In the initial phase of $\mathrm{AD}$, autophagy can be activated by $\mathrm{A} \beta$ formation, and the $\mathrm{A} \beta$ is likely to be degraded by autophagosome-lysosomal system [61]. Evidences suggest that $A \beta$ was expressed in the abnormal autophagic vesicles which could be a source of $A \beta$ extracellular plaque formation in a Drosophila model [62]. Autophagy may contribute to $A \beta$ secretion through a secretory pathway or a secretory lysosomal pathway; likewise, neuronal autophagy absence might reduce $A \beta$ secretion. For this reason, autophagy is suggested to play a bi-directional role in $A \beta$ degradation as well as secretion, and therefore, additional study on the dual character of autophagy in the clearance and secretion of $A \beta$ in pathogenesis of $A D$ is needed [63]. In the later stage of $A D$, the continuous addition of $A \beta$ induces abnormal autophagy, which leads to neuronal dysfunction and accelerates $\mathrm{AD}$ symptoms. The toxic form of $\mathrm{A} \beta, \mathrm{A} \beta$-derived diffusible ligands (ADLLs), is involved in AD development and regulates autophagy [64]. The exposure of ADLLs to neuronal cells decreased phosphorylated p70S6K1, indicating that mTOR inhibition causes an intricate outcome in ADLLs-mediated abnormal autophagy [64]. A $\beta$ increases ROS generation and the hyperactivation of autophagy via NOX4 upregulation, leading to neuronal cell death [28]. Interestingly, reduction of NOX4 as well as ROS levels can prevent autophagy from overactivation as well as neuronal cell death. RAGE, receptor of advanced glycation end-products, is a main receptor in facilitating the toxicity of $A \beta$ [65], and $A \beta 1-42$ mediates abnormal autophagy through the RAGE-associated pathway [65]. The treatment with A $\beta$ peptide induces autophagy dysfunction in astrocytes where p62 was aggregated and LC3-I/LC3-II transformation was decreased [66]. The mitochondrial abnormalities caused by $A \beta$-mediated dysfunction of the voltage-dependent anion channel 1 protein (VDAC1) as well as dynamin-related protein 1 (Drp1) [67]. Mitophagy promotes the removal of injured mitochondria, where PTEN-induced putative kinase 1 (PINK1) plays a vital role in regulating mitochondrial function [68]. The lower levels of PINK1 were linked to the pathology of $A \beta$. In AD, PINK1-mediated pathology of A $\beta$ with mitophagy promoting to the cognitive and synaptic dysfunction [69]. Interestingly, overexpression of PINK1 enhanced the removal of injured mitochondria through upholding mitophagy in AD. In 
an AD mouse model, the hippocampal A $\beta$ decreases PINK1 expression, which reduces mitophagy and causes cognitive decay [5].

\section{THEREPEUTIC ACTION OF APP TREIGGRING BY AUTOPHAGY}

AD incidence has posed a global health burden on elderly people, and is predicted to increase significantly worldwide. A considerable effort to develop drugs for the treatment of $\mathrm{AD}$ has been devoted, focusing on drug structures, and potential molecular mechanisms of AD. An example of generally accepted hypotheses is that the reduced levels of acetylcholine cause AD in neurons. However, drugs targeting acetylcholine so called "cholinesterase inhibitors" could poorly improve $\mathrm{AD}[70,71]$. Therefore, targeting other drugs which comprise potential autophagy regulators that have a greater possibility for the treatment of $\mathrm{AD}$.

\subsection{Use of small molecules to modulate autophagy in AD}

Another hallmark regarding the pathogenesis of AD is the accumulation of amyloid beta proteins and hyperphosphorylated tau which are considered toxic to neurons [72]. Dysregulated or insufficient autophagy might be causative factors behind the development and progression of AD [14], and therefore, the discovery of drugs targeting autophagy-related signaling pathways might be an attractive approach for the treatment and management of AD [11]. The potential candidates of small molecules which is likely to be involved in the regulation of autophagy pathways and their implication on AD therapy is summarized in Figure 6. 


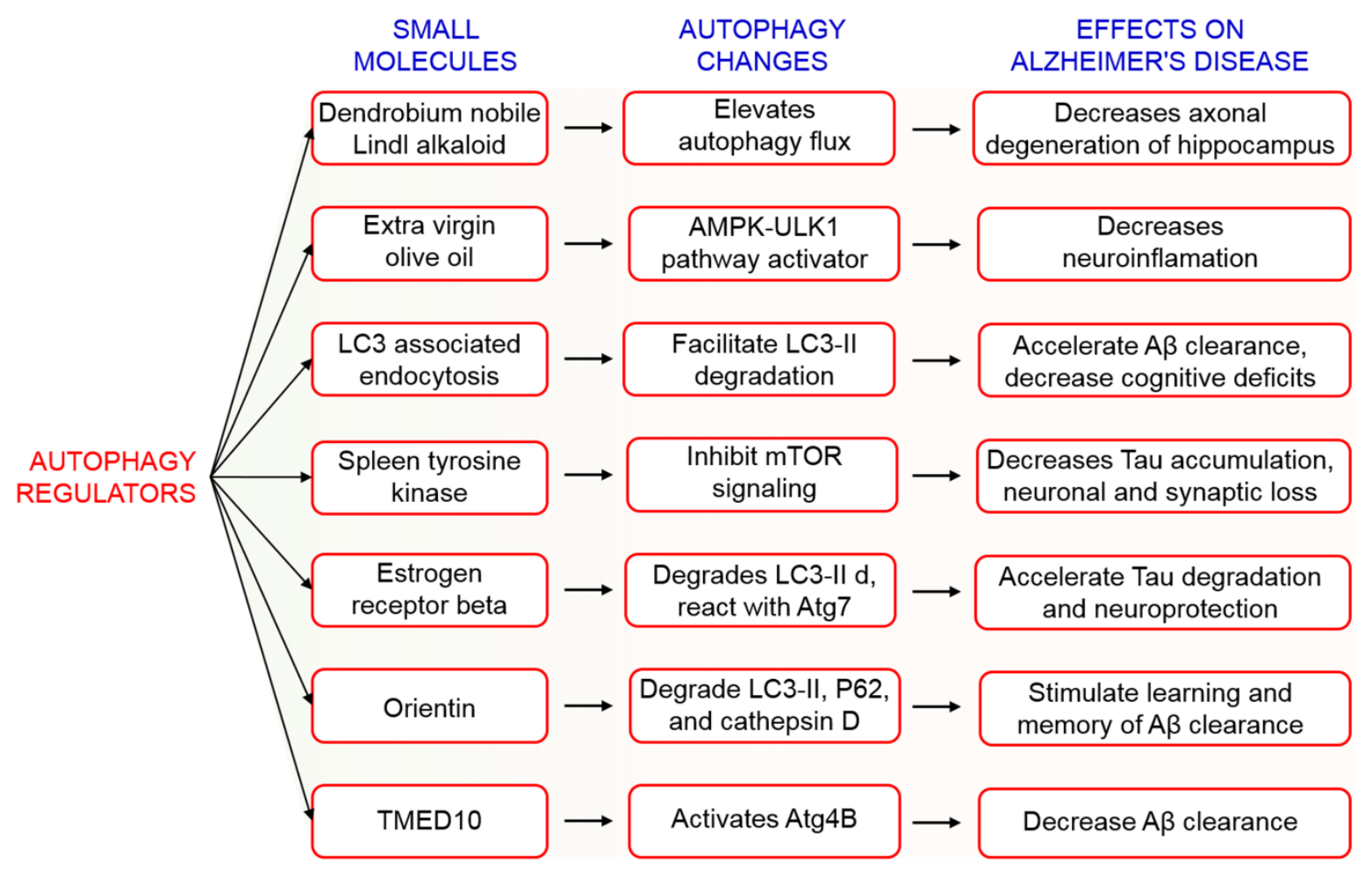

Figure 6: Implication of several small molecules to modulate autophagy and their action in AD treatments.

\subsection{Use of natural compound to modulate autophagy in AD}

Natural products and herbal medicine may be used for the management of neurodegeneration, cancer, and apoptosis [73-80] as well as autophagy inducer [81]. Recent studies revealed that active compounds in natural products exhibit curative effects against $\mathrm{AD}$ via a variety of mechanisms, including anti-cholinesterase activity, anti-apoptosis, and neuroprotective effects via antioxidation through targeting autophagy $[82,83]$. Emerging evidence suggests that the natural compounds are attractive sources of autophagy regulators [82,84]. Integrating reports demonstrate that the active compounds regulating autophagy process pave a new therapeutic way for neurodegenerative diseases $[85,86]$. Examples of plant-derived active components ameliorating the symptoms of AD via targeting autophagy are summarized in Table 1.

Alkaloids are important examples of active compounds isolated from plants and show anticholinesterase and modulatory effects on autophagy implicated in the treatment of neurodegenerative diseases. For instance, alkaloids can modulate autophagy in AD [87], and 
Dendrobium nobile Lindl extracts possess alkaloids components that are capable of hindering axonal degeneration [88]. Plant alkaloid berberine ameliorated learning and memory functions, and accelerated $\mathrm{A} \beta$ clearance in an AD mouse model [89]. Berberine can also promote autophagy processes in the brain [90], and has a neuroprotective activity [91]. An oxindole alkaloid called Corynoxine obtained from Uncaria rhynchophylla (Miq.) is another example of autophagy enhancers [92]. Moreover, an isomer of Corynoxine, corynoxine B, was shown to promote autophagy and reduced the accumulation of A $\beta$ levels by facilitating the degradation of APP [93].

Table 1: Modulation of autophagy by natural products, and their therapeutic implication in Alzheimer's disease

\begin{tabular}{|c|c|c|c|c|}
\hline $\begin{array}{l}\text { Natural } \\
\text { products }\end{array}$ & AD Model & $\begin{array}{l}\text { Activities/ } \\
\text { Effects }\end{array}$ & $\begin{array}{l}\text { Molecular } \\
\text { mechanism }\end{array}$ & $\begin{array}{c}\text { Referenc } \\
\text { es }\end{array}$ \\
\hline Ginsenoside Rg2 & $\begin{array}{l}5 \times \mathrm{FAD} \\
\text { transgenic } \\
\text { mice }\end{array}$ & $\begin{array}{l}\text { Removal of } \mathrm{A} \beta \\
\text { aggregation }\end{array}$ & $\begin{array}{c}\text { AMPK/ULK1- } \\
\text { mediated autophagy } \\
\text { induction }\end{array}$ & [94] \\
\hline $\begin{array}{c}\text { Protopanaxadiol } \\
\text { derivative DDPU }\end{array}$ & $\begin{array}{l}\text { APP/PS1 mice } \\
\text { model }\end{array}$ & $\begin{array}{c}\text { Stimulate the } \\
\text { clearance of } A \beta\end{array}$ & $\begin{array}{c}\text { Inhibition of } \\
\text { PI3K/mTOR- } \\
\text { mediated autophagy } \\
\text { induction }\end{array}$ & [95] \\
\hline Berberine & $3 \times \mathrm{Tg}-\mathrm{AD}$ mice & $\begin{array}{c}\text { Promote the } \\
\text { clearance of } A \beta\end{array}$ & $\begin{array}{c}\text { Activate } \\
\text { Bcl2/Beclin1- } \\
\text { mediated } \\
\text { autophagy induction }\end{array}$ & [96] \\
\hline $\begin{array}{l}\text { Flavonoids } \\
\text { Silibinin }\end{array}$ & $\begin{array}{c}\mathrm{A} \beta 1-42 \text {-induced } \\
\text { rat } \\
\text { model }\end{array}$ & $\begin{array}{c}\text { Attenuate } \\
\text { neuronal } \\
\text { damage }\end{array}$ & Inhibit autophagy & [97] \\
\hline Corynoxine B & $\begin{array}{l}\text { Tg2567 mice, } \\
\text { N2a-SwedAPP } \\
\text { cell model }\end{array}$ & $\begin{array}{c}\text { Augment APP } \\
\text { and } \\
\text { A } \beta \text { degradation }\end{array}$ & $\begin{array}{l}\text { Unclear pathway to } \\
\text { induce autophagy }\end{array}$ & [93] \\
\hline Gypenoside XVII & $\begin{array}{l}\text { APP/PS1 } \\
\text { transgenic } \\
\text { mice }\end{array}$ & $\begin{array}{c}\text { Prevent } A \beta \\
\text { accumulation }\end{array}$ & $\begin{array}{l}\text { Promote TFEB to } \\
\text { induce autophagy }\end{array}$ & [98] \\
\hline $\begin{array}{l}\text { Ginkgo biloba } \\
\text { extract }\end{array}$ & TgCRND8 mice & $\begin{array}{l}\text { Improve } \\
\text { cognitive } \\
\text { function }\end{array}$ & Induce autophagy & [99] \\
\hline $\begin{array}{l}\text { Radix polygalae } \\
\text { extract }\end{array}$ & $\begin{array}{l}\text { Cell model of } \\
\text { CHO- } \\
\text { APP/BACE1 } \\
\end{array}$ & $\begin{array}{l}\mathrm{A} \beta 1-40 \\
\text { decrease }\end{array}$ & $\begin{array}{c}\text { Activate } \\
\text { AMPK/mTOR and } \\
\text { promote autophagy }\end{array}$ & [100] \\
\hline Madecassoside & $\begin{array}{l}\text { D-galactose- } \\
\text { induced }\end{array}$ & $\begin{array}{l}\text { Autophagy } \\
\text { inhibition }\end{array}$ & $\begin{array}{c}\text { Rise Bcl-2 and } \\
\text { decrease Beclin-1 }\end{array}$ & [101] \\
\hline
\end{tabular}




\begin{tabular}{|c|c|c|c|c|}
\hline & mouse model & & & \\
\hline Hesperetin & $\mathrm{N} 2 \mathrm{a}$ cell model & $\begin{array}{c}\text { Increase } A \beta- \\
\text { damaged }\end{array}$ & $\begin{array}{l}\text { Autophagy } \\
\text { inhibition }\end{array}$ & [102] \\
\hline Morus alba extract & SH-SY5Y cell & $\begin{array}{l}\text { Autophagy } \\
\text { induction }\end{array}$ & $\begin{array}{l}\text { mTOR dependent } \\
\text { autophagy pathway }\end{array}$ & {$[74,82]$} \\
\hline Wogonin & $\begin{array}{l}\text { SH-SY5Y-APP } \\
\text { primary cortical } \\
\text { astrocytes }\end{array}$ & $\begin{array}{c}\text { Enhance } A \beta \\
\text { removal }\end{array}$ & $\begin{array}{c}\text { Activate } \\
\text { ULK1/mTOR and } \\
\text { induce autophagy }\end{array}$ & [103] \\
\hline Curcumin & $\begin{array}{l}\text { APP/PS1 } \\
\text { transgenic } \\
\text { mice } \\
\end{array}$ & $\begin{array}{l}\text { Prevent } A \beta \\
\text { deposition }\end{array}$ & $\begin{array}{c}\text { Inhibit PI3K/mTOR } \\
\text { and induce } \\
\text { autophagy }\end{array}$ & [104] \\
\hline Resveratrol & $\begin{array}{l}\text { N2a-APP cell, } \\
\text { HEK293-APP } \\
\text { cell }\end{array}$ & $\begin{array}{c}\text { Decrease } A \beta \\
\text { production and } \\
\text { aggregation }\end{array}$ & $\begin{array}{c}\text { Induce autophagy by } \\
\text { activating } \\
\text { AMPK/mTOR } \\
\text { signaling }\end{array}$ & {$[105,106]$} \\
\hline Sulforaphane & AD model & Nrf2 signaling & Induce autophagy & [107] \\
\hline Carnosic acid & $\begin{array}{l}\text { A } \beta 25-35 \text {-induced } \\
\text { SHSY5Y cell }\end{array}$ & $\begin{array}{c}\text { Inhibition of } \\
\text { A } \beta 1-42 \\
\text { aggregation }\end{array}$ & $\begin{array}{c}\text { Activate } \\
\text { AMPK/mTOR and } \\
\text { induce autophagy }\end{array}$ & [108] \\
\hline Tripchlorolide & $\begin{array}{c}5 \times \mathrm{FAD} \\
\text { transgenic } \\
\text { mice }\end{array}$ & $\begin{array}{l}\text { Reduce cerebral } \\
\text { A } \beta \text { deposits }\end{array}$ & $\begin{array}{c}\text { Activate } \\
\text { PI3K/mTOR } \\
\text { pathway } \\
\end{array}$ & [109] \\
\hline$\beta$-asarone & $\begin{array}{l}\text { APP/PS1 } \\
\text { transgenic } \\
\text { mice }\end{array}$ & $\begin{array}{c}\text { Decrease } A \beta \\
\text { level }\end{array}$ & $\begin{array}{c}\text { Activate } \\
\text { PI3K/mTOR and } \\
\text { inhibit autophagy }\end{array}$ & [110] \\
\hline Oxyresveratrol & $\begin{array}{l}\text { SH-SY5Y cell } \\
\text { model }\end{array}$ & $\begin{array}{l}\text { Stimulate } \\
\text { autophagy }\end{array}$ & $\begin{array}{l}\text { Atg5/7, Beclin-1, } \\
\text { and LC-3 induction }\end{array}$ & [24] \\
\hline $\begin{array}{l}\text { 18a-Glycyrrhetinic } \\
\text { acid }\end{array}$ & $\begin{array}{l}\text { SH-SY5Y cell } \\
\text { model }\end{array}$ & $\begin{array}{c}\text { Induction of } \\
\text { autophagy flux }\end{array}$ & $\begin{array}{l}\text { mTOR dependent } \\
\text { autophagy induction }\end{array}$ & [23] \\
\hline Gintonin & $\begin{array}{c}\text { Mouse cortical } \\
\text { Astrocytes }\end{array}$ & $\begin{array}{c}\text { Autophagic flux } \\
\text { induction }\end{array}$ & $\begin{array}{l}\text { Beclin-1, Atg5/7, } \\
\text { LAMP-1 induction }\end{array}$ & {$[22]$} \\
\hline Emodin & APP/PS1 mice & $\begin{array}{l}\text { Autophagy } \\
\text { inhibition }\end{array}$ & $\begin{array}{c}\text { Activate Bcl-2/ } \\
\text { Beclin-1/PIK3C3 } \\
\text { pathway }\end{array}$ & [93] \\
\hline
\end{tabular}

Many studies demonstrated that active components of flavonoids can affect autophagy in various diseases. Silybum marianum possessed plant flavonoid Silibinin ameliorated A $\beta 1-42$-induced depression in rats, and it alleviated damage of neurons in the hippocampus via inhibiting autophagy [97]. Another flavonoid component wogonin isolated from Scutellaria baicalensis enhances A $\beta$ clearance in cortical astrocytes and reduces $A \beta$ deposition via modulating autophagy signaling 
pathway [103]. Moreover, hesperetin and its glycoside hesperidin is implicated in the protection of neuron cells via decreasing A $\beta$-mediated autophagy [102].

A variety of products isolated from Panax Ginseng have also been shown to provide neuroprotection and to ameliorate memory function in dementia [111]. For example, Rg2 ginseng triggers autophagy [94], accelerates the clearance of aggregated proteins, increases the accumulation of cerebral $A \beta$, and ameliorates cognitive functions via autophagy in a mouse model of AD [93]. Protopanaxadiol is associated with axonal outgrowth in neuronal degeneration, and it can ameliorate memory disorders of AD mice [95]. DDPU was implicated in the development of AD behavior in associated with autophagy [95]. Another alkaloid gypenoside XVII found in ginseng Panax notoginseng enhanced the removal of amyloidal deposition in the hippocampus and cortex of mice, and Gypenoside XVII also exert a neuroprotective effect on AD via triggering autophagy [98]. Madecassoside, a triterpenoid saponin compound, inhibits autophagy through increasing the levels of Bcl-2 and decreasing Beclin-1 in neuronal cells [101]. It has also been observed that madecassoside improves cognitive function and synaptic plasticity in the AD mice model [112]. However, O-GlcNAcylation modulation has been regulated autophagy in astrocytes and control antidepressant-like phenotype in neurons [113,114]. Gintonin has been used for the treatment or prevention of AD through elevation of hippocampal neurogenesis in APPswe/PSEN1 double Tg mouse model of AD [115], and it is demonstrated that gintonin-mediated treatment is nontoxic and possibly beneficial in cognitively impaired elderly in AD [116].

Curcumin relieves cognitive impairment and inhibits $A \beta$ formation by blocking autophagy through $\mathrm{PI} 3 \mathrm{~K} / \mathrm{Akt} / \mathrm{mTOR}$ downregulation pathway [104]. A polyphenol resveratrol is being considered widely because of its use in AD model [117]. Recently, it has been found that decreasing the production of $A \beta$ hinders the development of $A D$. The synthesis of $A \beta$ was declined in the cells via influencing the signaling pathways such as triggering AMPK as well as preventing mTOR to activate autophagy. It was also reported that oral administration of resveratrol suppressed $A \beta$ accumulation in the cortex [118]. One of the primal bioactive components, tetrahydroxystilbene2-O-glycoside of Radix Polygoni multiflori, decreases APP expression and enhances the cognitive activity in transgenic AD mice via reducing Beclin-1 as well as LC3-II expression through autophagy [93]. Emodin, obtained from Rheum palmatum L., has been involved to treat in AD by reducing LC3-II expression; however, it increases Bcl-2 expression [93]. The polyphenolic 
Carnosic acid of Rosemarinus officinalis is involved in the reduction of neurotoxicity induced by amyloidal deposition, and decreases the accumulation of amyloidal aggregates and hyperphosphorylation of tau [108]. The consumption of Ginkgo biloba extract enhanced the cognitive and synaptic function AD mice model through partially activating the autophagy [99]. Besides, some compounds having special structural features, such as arctigenin, tripchlorolide and $\beta$-asarone were shown to improve memory by modulating autophagy-related signaling pathways. The significant levels of arctigenin were observed in the brain, indicating that it might not cross the blood-brain barrier [119]. Therefore, natural products might be considered as the therapeutic target for the management of AD.

\subsection{Use of FDA-approved drugs to modulate autophagy in AD}

Clomipramine, an FDA-approved drug used for the treatment of psychiatric disorders, was shown to block the fusion of autophagosome and lysosome, thus interfering with autophagic flux [120]. Benzoporphyrin derivative, another FDA-approved drug known as verteporfin, is likely to inhibit formation of autophagosome in presence of chloroquine (CQ), a lysosomal inhibitor [121]. APP 5' UTR-directed drugs decreased APP in SH-SY5Y neuroblastoma cells [122]. In figure 7, we represented that lower levels of $A \beta$ peptide was achieved by FDA-preapproved drugs that lowered intracellular APP holoprotein levels in the SH-SY5Y cell model [123]. The pharmacological action of DMP, DFO, paroxetine, phenserine, and tetrathiolmobdylate to decrease the levels of APP and A $\beta$ peptide is described in Figure 7. Azithromycin dramatically changed the processing of APP [124]. Thus, it has been described that a subsection of drugs that have been selected to stimulate APP 5' UTR-mediated translation are furthermore as a coactivators of nonamyloidogenic pathway of APP processing. 


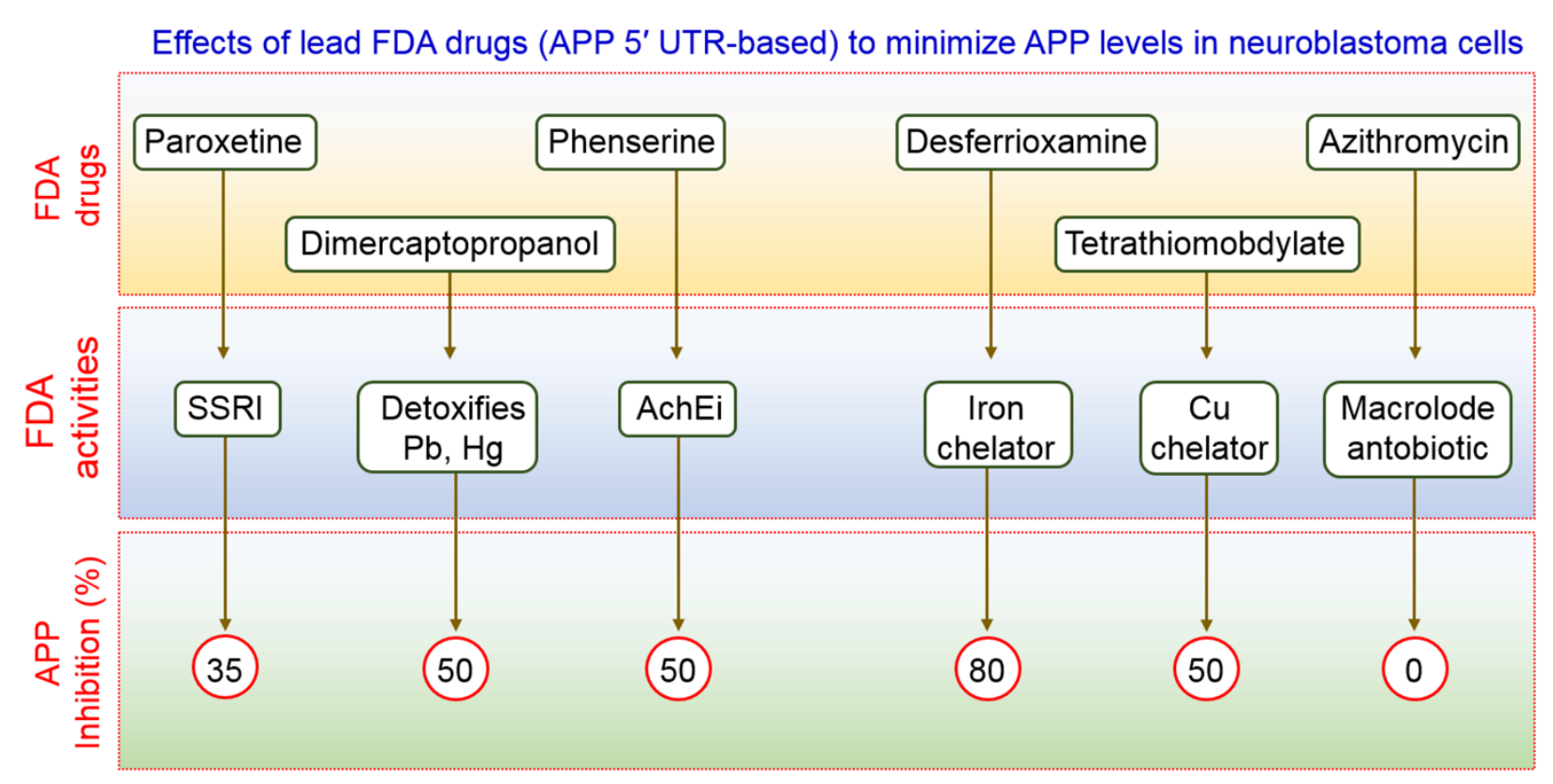

Figure 7: Effects on FDA-approved drug used for the treatment of AD-associated disorders.

\section{Conclusion}

From the above discussion, it has been implicated that autophagy is an important cellular process in $\mathrm{AD}$ pathogenesis, which regulates the production and degradation of primary pathological proteins, such as $A \beta$ and p-tau. While autophagy shows a dual role in the case of $A D$, systematic research with new evidence will provide information on the modulation of autophagy process in AD treatment. Taken together, recent studies demonstrate that a variety of bioactive components from medicinal herbs, small molecules, and FDA drugs are likely to improve AD via the modulation of autophagy pathway. 


\section{Authors' Contributions}

This collaboration work was carried out among all authors. MAR designed the outline and wrote the draft. MSR prepared the figures. MR, MRR, MJU and ANMMR wrote some part of the manuscript. MGP reviewed the manuscript. HR proposed the original idea of this manuscript. HH reviewed the scientific contents of the manuscript. All authors read and approved the final version of this manuscript.

\section{Acknowledgements}

This work was supported by the Korea Research Fellowship (KRF) Program (2016H1D3A1908615, 2017H1D3A1A02013844) through the National Research Foundation of Korea and the NRF Research Program (2016M3C7A1913845) funded by the Ministry of Science and ICT, Republic of Korea. Additionally, this is supported by the RP-Grant 2020 of Ewha Womans University, Republic of Korea.

\section{Conflict of Interest}

The authors declare that they have no conflict of interest. 


\section{References}

[1] R.J. O'Brien, P.C. Wong, Amyloid precursor protein processing and Alzheimer's disease, Annu Rev Neurosci 34 (2011) 185-204. 10.1146/annurev-neuro-061010-113613.

[2] Y.W. Zhang, R. Thompson, H. Zhang, H. Xu, APP processing in Alzheimer's disease, Mol Brain 4 (2011) 3. 10.1186/1756-6606-4-3.

[3] V.J. De-Paula, M. Radanovic, B.S. Diniz, O.V. Forlenza, Alzheimer's disease, Subcell Biochem 65 (2012) 329-352. 10.1007/978-94-007-5416-4_14.

[4] J.P. Greenfield, J. Tsai, G.K. Gouras, B. Hai, G. Thinakaran, F. Checler, S.S. Sisodia, P. Greengard, H. Xu, Endoplasmic reticulum and trans-Golgi network generate distinct populations of Alzheimer beta-amyloid peptides, Proc Natl Acad Sci U S A 96 (1999) 742-747. 10.1073/pnas.96.2.742.

[5] M. Manczak, R. Kandimalla, X. Yin, P.H. Reddy, Hippocampal mutant APP and amyloid beta-induced cognitive decline, dendritic spine loss, defective autophagy, mitophagy and mitochondrial abnormalities in a mouse model of Alzheimer's disease, Hum Mol Genet 27 (2018) 1332-1342. 10.1093/hmg/ddy042.

[6] R.P. Friedrich, K. Tepper, R. Ronicke, M. Soom, M. Westermann, K. Reymann, C. Kaether, M. Fandrich, Mechanism of amyloid plaque formation suggests an intracellular basis of Abeta pathogenicity, Proc Natl Acad Sci U S A 107 (2010) 1942-1947. 10.1073/pnas.0904532106.

[7] E. Ercan-Herbst, J. Ehrig, D.C. Schondorf, A. Behrendt, B. Klaus, B. Gomez Ramos, N. Prat Oriol, C. Weber, D.E. Ehrnhoefer, A post-translational modification signature defines changes in soluble tau correlating with oligomerization in early stage Alzheimer's disease brain, Acta Neuropathol Commun 7 (2019) 192. 10.1186/s40478-019-0823-2.

[8] A. Mietelska-Porowska, U. Wasik, M. Goras, A. Filipek, G. Niewiadomska, Tau Protein Modifications and Interactions: Their Role in Function and Dysfunction, Int J Mol Sci 15 (2014) 4671-4713. 10.3390/ijms15034671.

[9] C. Zhang, A. Browne, D.Y. Kim, R.E. Tanzi, Familial Alzheimer's Disease Mutations in Presenilin 1 Do Not Alter Levels of the Secreted Amyloid-Protein Precursor Generated by beta-Secretase Cleavage, Curr Alzheimer Res 7 (2010) 21-26. Doi 10.2174/156720510790274428.

[10] R. Rajmohan, P.H. Reddy, Amyloid-Beta and Phosphorylated Tau Accumulations Cause Abnormalities at Synapses of Alzheimer's disease Neurons, J Alzheimers Dis 57 (2017) 975-999. 10.3233/Jad-160612.

[11] M.A. Rahman, H. Rhim, Therapeutic implication of autophagy in neurodegenerative diseases, BMB Rep 50 (2017) 345-354. 10.5483/bmbrep.2017.50.7.069.

[12] E. Schmukler, R. Pinkas-Kramarski, Autophagy induction in the treatment of Alzheimer's disease, Drug Dev Res (2019). 10.1002/ddr.21605.

[13] M. Rasheduzzaman, H. Yin, S.Y. Park, Cardiac glycoside sensitized hepatocellular carcinoma cells to TRAIL via ROS generation, p38MAPK, mitochondrial transition, and autophagy mediation, Mol Carcinog 58 (2019) 2040-2051. 10.1002/mc.23096.

[14] M.S. Uddin, A.A. Mamun, Z.K. Labu, O. Hidalgo-Lanussa, G.E. Barreto, G.M. Ashraf, Autophagic dysfunction in Alzheimer's disease: Cellular and molecular mechanistic approaches to halt Alzheimer's pathogenesis, J Cell Physiol 234 (2019) 8094-8112. 10.1002/jcp.27588.

[15] Z. Mputhia, E. Hone, T. Tripathi, T. Sargeant, R. Martins, P. Bharadwaj, Autophagy Modulation as a Treatment of Amyloid Diseases, Molecules 24 (2019). ARTN 3372

10.3390/molecules24183372.

[16] Y. Wan, Y. Liang, F. Liang, N. Shen, K. Shinozuka, J.T. Yu, C. Ran, Q. Quan, R.E. Tanzi, C. Zhang, A Curcumin Analog Reduces Levels of the Alzheimer's Disease-Associated Amyloid-beta Protein by Modulating AbetaPP Processing and Autophagy, J Alzheimers Dis 72 (2019) 761-771. 10.3233/JAD-190562. 
[17] N. Mizushima, Autophagy: process and function, Genes Dev 21 (2007) 2861-2873. 10.1101/gad.1599207.

[18] Y. Kabeya, N. Mizushima, T. Ueno, A. Yamamoto, T. Kirisako, T. Noda, E. Kominami, Y. Ohsumi, T. Yoshimori, LC3, a mammalian homolog of yeast Apg8p, is localized in autophagosome membranes after processing (vol 19, pg 5720, 2000), Embo J 22 (2003) 4577-4577.

[19] S. Liang, R. Uchiyama, Y.S. Roh, K. Ohashi, Z.Y. Zhong, E. Seki, Macrophage autophagy controls mitochondrial quality and IRF1 expression that regulates alcohol-induced liver injury in mice., Hepatology 64 (2016) 23a-23a.

[20] S. Sarkar, Regulation of autophagy by mTOR-dependent and mTOR-independent pathways: autophagy dysfunction in neurodegenerative diseases and therapeutic application of autophagy enhancers, Biochem Soc T 41 (2013) 1103-1130. 10.1042/Bst20130134.

[21] M.S. Uddin, M.A. Rahman, M.T. Kabir, T. Behl, B. Mathew, A. Perveen, G.E. Barreto, M.N. Bin-Jumah, M.M. Abdel-Daim, G.M. Ashraf, Multifarious roles of mTOR signaling in cognitive aging and cerebrovascular dysfunction of Alzheimer's disease, lubmb Life (2020). 10.1002/iub.2324.

[22] M.A. Rahman, H. Hwang, S.Y. Nah, H. Rhim, Gintonin stimulates autophagic flux in primary cortical astrocytes, J Ginseng Res 44 (2020) 67-78. 10.1016/j.jgr.2018.08.004.

[23] M.A. Rahman, K. Bishayee, K. Habib, A. Sadra, S.O. Huh, 18alpha-Glycyrrhetinic acid lethality for neuroblastoma cells via de-regulating the Beclin-1/Bcl-2 complex and inducing apoptosis, Biochem Pharmacol 117 (2016) 97-112. 10.1016/j.bcp.2016.08.006.

[24] M.A. Rahman, K. Bishayee, A. Sadra, S.O. Huh, Oxyresveratrol activates parallel apoptotic and autophagic cell death pathways in neuroblastoma cells, Bba-Gen Subjects 1861 (2017) 23-36. 10.1016/j.bbagen.2016.10.025.

[25] L. Ordonez-Gutierrez, I. Benito-Cuesta, J.L. Abad, J. Casas, G. Fabrias, F. Wandosell, Dihydroceramide Desaturase 1 Inhibitors Reduce Amyloid-beta Levels in Primary Neurons from an Alzheimer's Disease Transgenic Model, Pharm Res-Dordr 35 (2018). UNSP 49

10.1007/s11095-017-2312-2.

[26] H. Martini-Stoica, Y. Xu, A. Ballabio, H. Zheng, The Autophagy-Lysosomal Pathway in Neurodegeneration: A TFEB Perspective, Trends Neurosci 39 (2016) 221-234. 10.1016/j.tins.2016.02.002. [27] M. Rasheduzzaman, J.H. Moon, J.H. Lee, U.M. Nazim, S.Y. Park, Telmisartan generates ROSdependent upregulation of death receptor 5 to sensitize TRAIL in lung cancer via inhibition of autophagy flux, Int J Biochem Cell Biol 102 (2018) 20-30. 10.1016/j.biocel.2018.06.006.

[28] M. Cordani, M. Sanchez-Alvarez, R. Strippoli, A.V. Bazhin, M. Donadelli, Sestrins at the Interface of ROS Control and Autophagy Regulation in Health and Disease, Oxidative Medicine and Cellular Longevity (2019). Artn 1283075

10.1155/2019/1283075.

[29] A. Di Meco, J.G. Li, B.E. Blass, M. Abou-Gharbia, E. Lauretti, D. Pratico, 12/15-Lipoxygenase Inhibition Reverses Cognitive Impairment, Brain Amyloidosis, and Tau Pathology by Stimulating Autophagy in Aged Triple Transgenic Mice, Biol Psychiat 81 (2017) 92-100. 10.1016/j.biopsych.2016.05.023.

[30] M.P. Murphy, How mitochondria produce reactive oxygen species, Biochem J 417 (2009) 1-13. 10.1042/Bj20081386.

[31] F.K. Liu, J. Huang, L.Y. Zhang, J.D. Chen, Y. Zeng, Y.J. Tang, Z.X. Liu, Advances in Cerebral Organoid Systems and their Application in Disease Modeling, Neuroscience 399 (2019) 28-38. 10.1016/j.neuroscience.2018.12.013.

[32] N.T. Tue, T.Q. Dat, L.L. Ly, V.D. Anh, H. Yoshida, Insights from Drosophila melanogaster model of Alzheimer's disease, Front Biosci (Landmark Ed) 25 (2020) 134-146. 
[33] K. Ren, R. Dubner, Activity-triggered tetrapartite neuron-glial interactions following peripheral injury, Curr Opin Pharmacol 26 (2016) 16-25. 10.1016/j.coph.2015.09.006.

[34] E.A. Saburova, A.N. Vasiliev, V.V. Kravtsova, E.V. Ryabova, A.L. Zefirov, O.I. Bolshakova, S.V. Sarantseva, I.I. Krivoi, Human APP Gene Expression Alters Active Zone Distribution and Spontaneous Neurotransmitter Release at the Drosophila Larval Neuromuscular Junction, Neural Plast (2017). Artn 9202584

10.1155/2017/9202584.

[35] K. Koga, M.G. Liu, S. Qiu, Q. Song, G. O'Den, T. Chen, M. Zhuo, Impaired Presynaptic Long-Term Potentiation in the Anterior Cingulate Cortex of Fmr1 Knock-out Mice, J Neurosci 35 (2015) 2033-2043. 10.1523/Jneurosci.2644-14.2015.

[36] A.C. McKee, D.H. Daneshvar, The neuropathology of traumatic brain injury, Handb Clin Neurol 127 (2015) 45-66. 10.1016/B978-0-444-52892-6.00004-0.

[37] M.A. Sugarman, A.C. McKee, T.D. Stein, Y. Tripodis, L.M. Besser, B. Martin, J.N. Palmisano, E.G. Steinberg, M.K. O'Connor, R. Au, M. McClean, R. Killiany, J. Mez, M.W. Weiner, N.W. Kowall, R.A. Stern, M.L. Alosco, Failure to detect an association between self-reported traumatic brain injury and Alzheimer's disease neuropathology and dementia, Alzheimers Dement 15 (2019) 686-698. 10.1016/j.jalz.2018.12.015. [38] M.P. Marzolo, G. Bu, Lipoprotein receptors and cholesterol in APP trafficking and proteolytic processing, implications for Alzheimer's disease, Semin Cell Dev Biol 20 (2009) 191-200. 10.1016/j.semcdb.2008.10.005.

[39] C. Haass, C. Kaether, G. Thinakaran, S. Sisodia, Trafficking and proteolytic processing of APP, Cold Spring Harb Perspect Med 2 (2012) a006270. 10.1101/cshperspect.a006270.

[40] V.W. Chow, M.P. Mattson, P.C. Wong, M. Gleichmann, An Overview of APP Processing Enzymes and Products, Neuromol Med 12 (2010) 1-12. 10.1007/s12017-009-8104-z.

[41] M.A. Rahman, M.S. Rahman, M.J. Uddin, A.N.M. Mamum-Or-Rashid, M.G. Pang, H. Rhim, Emerging risk of environmental factors: insight mechanisms of Alzheimer's diseases, Environ Sci Pollut R (2020). 10.1007/s11356-020-08243-z.

[42] M.A. Castro, A. Hadziselimovic, C.R. Sanders, The vexing complexity of the amyloidogenic pathway, Protein Sci 28 (2019) 1177-1193. 10.1002/pro.3606.

[43] H.S. Nhan, K. Chiang, E.H. Koo, The multifaceted nature of amyloid precursor protein and its proteolytic fragments: friends and foes, Acta Neuropathol 129 (2015) 1-19. 10.1007/s00401-014-1347-2.

[44] H.M. Wilkins, R.H. Swerdlow, Amyloid precursor protein processing and bioenergetics, Brain Res Bull 133 (2017) 71-79. 10.1016/j.brainresbull.2016.08.009.

[45] J.A. Findlay, D.L. Hamilton, S. Sri, M. Vargas-Caballero, M.L.J. Ashford, P.J.S. Smith, Manipulation of Amyloid Precursor Protein Processing Impacts Brain Bioenergetics and Glucose Metabolism, Biophys J 112 (2017) 324a-324a. DOI 10.1016/j.bpj.2016.11.1756.

[46] B. De Strooper, R. Vassar, T. Golde, The secretases: enzymes with therapeutic potential in Alzheimer disease, Nat Rev Neurol 6 (2010) 99-107. 10.1038/nrneurol.2009.218.

[47] L.M. Bekris, N.M. Galloway, S. Millard, D. Lockhart, G. Li, D.R. Galasko, M.R. Farlow, C.M. Clark, J.F. Quinn, J.A. Kaye, G.D. Schellenberg, J.B. Leverenz, P. Seubert, D.W. Tsuang, E.R. Peskind, C.E. Yu, Amyloid precursor protein (APP) processing genes and cerebrospinal fluid APP cleavage product levels in Alzheimer's disease, Neurobiol Aging 32 (2011) 556 e513-523. 10.1016/j.neurobiolaging.2010.10.020.

[48] R. Bravo, V. Parra, D. Gatica, A.E. Rodriguez, N. Torrealba, F. Paredes, Z.V. Wang, A. Zorzano, J.A. Hill, E. Jaimovich, A.F.G. Quest, S. Lavandero, Endoplasmic Reticulum and the Unfolded Protein Response: Dynamics and Metabolic Integration, Int Rev Cel Mol Bio 301 (2013) 215-290. 10.1016/B978-0-12-4077041.00005-1. 
[49] A. Salminen, K. Kaarniranta, A. Kauppinen, J. Ojala, A. Haapasalo, H. Soininen, M. Hiltunen, Impaired autophagy and APP processing in Alzheimer's disease: The potential role of Beclin 1 interactome, Prog Neurobiol 106 (2013) 33-54. 10.1016/j.pneurobio.2013.06.002.

[50] R.A. Nixon, Autophagy, amyloidogenesis and Alzheimer disease, J Cell Sci 120 (2007) 4081-4091. $10.1242 /$ jcs.019265.

[51] S. Krishnaswamy, G. Verdile, D. Groth, L. Kanyenda, R.N. Martins, The structure and function of Alzheimer's gamma secretase enzyme complex, Crit Rev Cl Lab Sci 46 (2009) 282-301. 10.3109/10408360903335821.

[52] A.D. Alonso, T. Zaidi, M. Novak, I. Grundke-lqbal, K. Iqbal, Hyperphosphorylation induces selfassembly of tau into tangles of paired helical filaments/straight filaments, P Natl Acad Sci USA 98 (2001) 6923-6928. DOI 10.1073/pnas.121119298.

[53] S.L. Cole, R. Vassar, The Alzheimer's disease beta-secretase enzyme, BACE1, Mol Neurodegener 2 (2007) 22. 10.1186/1750-1326-2-22.

[54] F. Li, T. Chung, R.D. Vierstra, AUTOPHAGY-RELATED11 plays a critical role in general autophagy- and senescence-induced mitophagy in Arabidopsis, Plant Cell 26 (2014) 788-807. 10.1105/tpc.113.120014.

[55] Y. Tian, V. Bustos, M. Flajolet, P. Greengard, A small-molecule enhancer of autophagy decreases levels of Abeta and APP-CTF via Atg5-dependent autophagy pathway, FASEB J 25 (2011) 1934-1942. 10.1096/fj.10-175158.

[56] X. Ou, M.R. Lee, X. Huang, S. Messina-Graham, H.E. Broxmeyer, SIRT1 positively regulates autophagy and mitochondria function in embryonic stem cells under oxidative stress, Stem Cells 32 (2014) 1183-1194. 10.1002/stem.1641.

[57] C. Li, X.D. Gu, M. Lei, J.Y. Wu, J.Z. Jin, X.F. Shi, Z.Y. Zhu, V. Rukachaisirikul, L.H. Hu, T.Q. Wen, X. Shen, Thamnolia vermicularis extract improves learning ability in APP/PS1 transgenic mice by ameliorating both A beta and Tau pathologies, Acta Pharmacol Sin 38 (2017) 9-28. 10.1038/aps.2016.94.

[58] R.C. Luo, L.Y. Su, G.Y. Li, J. Yang, Q.J. Liu, L.X. Yang, D.F. Zhang, H.J. Zhou, M. Xu, Y. Fan, J.L. Li, Y.G. Yao, Activation of PPARA-mediated autophagy reduces Alzheimer disease-like pathology and cognitive decline in a murine model, Autophagy 16 (2020) 52-69. 10.1080/15548627.2019.1596488.

[59] Y.S. Kim, P. Silwal, S.Y. Kim, T. Yoshimori, E.K. Jo, Autophagy-activating strategies to promote innate defense against mycobacteria, Exp Mol Med 51 (2019) 151. 10.1038/s12276-019-0290-7.

[60] Z. Cai, Y. Zhou, Z. Liu, Z. Ke, B. Zhao, Autophagy dysfunction upregulates beta-amyloid peptides via enhancing the activity of gamma-secretase complex, Neuropsychiatr Dis Treat 11 (2015) 2091-2099. 10.2147/NDT.S84755.

[61] J. Liu, L. Li, Targeting Autophagy for the Treatment of Alzheimer's Disease: Challenges and Opportunities, Front Mol Neurosci 12 (2019) 203. 10.3389/fnmol.2019.00203.

[62] L. O'Keefe, D. Denton, Using Drosophila Models of Amyloid Toxicity to Study Autophagy in the Pathogenesis of Alzheimer's Disease, Biomed Res Int (2018). Artn 5195416

$10.1155 / 2018 / 5195416$.

[63] P. Nilsson, T.C. Saido, Dual roles for autophagy: degradation and secretion of Alzheimer's disease Abeta peptide, Bioessays 36 (2014) 570-578. 10.1002/bies.201400002.

[64] J. Wen, F. Fang, S.H. Guo, Y. Zhang, X.L. Peng, W.M. Sun, X.R. Wei, J.S. He, T. Hung, Amyloid betaDerived Diffusible Ligands (ADDLs) Induce Abnormal Autophagy Associated with Abeta Aggregation Degree, J Mol Neurosci 64 (2018) 162-174. 10.1007/s12031-017-1015-9.

[65] J. Derk, M. MacLean, J. Juranek, A.M. Schmidt, The Receptor for Advanced Glycation Endproducts (RAGE) and Mediation of Inflammatory Neurodegeneration, J Alzheimers Dis Parkinsonism 8 (2018). 10.4172/2161-0460.1000421. 
[66] A. Caccamo, E. Ferreira, C. Branca, S. Oddo, p62 improves AD-like pathology by increasing autophagy, Mol Psychiatry 22 (2017) 865-873. 10.1038/mp.2016.139.

[67] M. Manczak, P.H. Reddy, Abnormal interaction of VDAC1 with amyloid beta and phosphorylated tau causes mitochondrial dysfunction in Alzheimer's disease, Hum Mol Genet 21 (2012) 5131-5146. $10.1093 / \mathrm{hmg} / \mathrm{dds} 360$.

[68] B. Khalil, N. El Fissi, A. Aouane, M.J. Cabirol-Pol, T. Rival, J.C. Lievens, PINK1-induced mitophagy promotes neuroprotection in Huntington's disease, Cell Death Dis 6 (2015) e1617. 10.1038/cddis.2014.581.

[69] F. Du, Q. Yu, S. Yan, G. Hu, L.F. Lue, D.G. Walker, L. Wu, S.F. Yan, K. Tieu, S.S. Yan, PINK1 signalling rescues amyloid pathology and mitochondrial dysfunction in Alzheimer's disease, Brain 140 (2017) 32333251. 10.1093/brain/awx258.

[70] D. Volpato, U. Holzgrabe, Designing Hybrids Targeting the Cholinergic System by Modulating the Muscarinic and Nicotinic Receptors: A Concept to Treat Alzheimer's Disease, Molecules 23 (2018). 10.3390/molecules23123230.

[71] T.H. Ferreira-Vieira, I.M. Guimaraes, F.R. Silva, F.M. Ribeiro, Alzheimer's disease: Targeting the Cholinergic System, Curr Neuropharmacol 14 (2016) 101-115. 10.2174/1570159x13666150716165726.

[72] H. Fujiwara, S. Watanabe, M. Iwata, S. Ueda, M. Nobuhara, S. Wada-Kakuda, H. Misonou, T. Miyasaka, Inhibition of microtubule assembly competent tubulin synthesis leads to accumulation of phosphorylated tau in neuronal cell bodies, Biochem Biophys Res Commun 521 (2020) 779-785. 10.1016/j.bbrc.2019.10.191.

[73] M.A. Rahman, K. Bishayee, S.O. Huh, Angelica polymorpha Maxim Induces Apoptosis of Human SHSY5Y Neuroblastoma Cells by Regulating an Intrinsic Caspase Pathway, Molecules and Cells 39 (2016) 119128. 10.14348/molcells.2016.2232.

[74] Y.H. Kwon, K. Bishayee, A. Rahman, J.S. Hong, S.S. Lim, S.O. Huh, Morus alba Accumulates Reactive Oxygen Species to Initiate Apoptosis via FOXO-Caspase 3-Dependent Pathway in Neuroblastoma Cells, Mol Cells 38 (2015) 630-637. 10.14348/molcells.2015.0030.

[75] M.A. Rahman, J.S. Hong, S.O. Huh, Antiproliferative properties of Saussurea lappa Clarke root extract in SH-SY5Y neuroblastoma cells via intrinsic apoptotic pathway, Anim Cells Syst 19 (2015) 119-126. 10.1080/19768354.2015.1008041.

[76] M.A. Rahman, H. Yang, N.H. Kim, S.O. Huh, Induction of apoptosis by Dioscorea nipponica Makino extracts in human SH-SY5Y neuroblastoma cells via mitochondria-mediated pathway, Anim Cells Syst 18 (2014) 41-51. 10.1080/19768354.2014.880372.

[77] M.A. Rahman, H. Yang, S.S. Lim, S.O. Huh, Apoptotic Effects of Melandryum firmum Root Extracts in Human SH-SY5Y Neuroblastoma Cells, Exp Neurobiol 22 (2013) 208-213. 10.5607/en.2013.22.3.208.

[78] M.A. Rahman, N.H. Kim, S.O. Huh, Cytotoxic effect of gambogic acid on SH-SY5Y neuroblastoma cells is mediated by intrinsic caspase-dependent signaling pathway, Mol Cell Biochem 377 (2013) 187-196. 10.1007/s11010-013-1584-z.

[79] M.A. Rahman, N.H. Kim, S.H. Kim, S.M. Oh, S.O. Huh, Antiproliferative and Cytotoxic Effects of Resveratrol in Mitochondria-Mediated Apoptosis in Rat B103 Neuroblastoma Cells, Korean J Physiol Pha 16 (2012) 321-326. 10.4196/kjpp.2012.16.5.321.

[80] M.A. Rahman, N.H. Kim, H. Yang, S.O. Huh, Angelicin induces apoptosis through intrinsic caspasedependent pathway in human SH-SY5Y neuroblastoma cells, Mol Cell Biochem 369 (2012) 95-104. 10.1007/s11010-012-1372-1.

[81] M.A. Rahman, S.K. Saha, M.S. Rahman, M.J. Uddin, M.S. Uddin, M.G. Pang, H. Rhim, S.G. Cho, Molecular Insights Into Therapeutic Potential of Autophagy Modulation by Natural Products for Cancer Stem Cells, Front Cell Dev Biol 8 (2020). ARTN 283 
10.3389/fcell.2020.00283.

[82] M.A. Rahman, M.R. Rahman, T. Zaman, M.S. Uddin, R. Islam, M.M. Abdel-Daim, H. Rhim, Emerging Potential of Naturally Occurring Autophagy Modulator against Neurodegeneration, Curr Pharm Des (2020). 10.2174/1381612826666200107142541.

[83] M.S. Uddin, A. Al Mamun, M. Jakaria, S. Thangapandiyan, J. Ahmad, M.A. Rahman, B. Mathew, M.M. Abdel-Daim, L. Aleya, Emerging promise of sulforaphane-mediated Nrf2 signaling cascade against neurological disorders, Science of the Total Environment 707 (2020). ARTN 135624

10.1016/j.scitotenv.2019.135624.

[84] V. Naponelli, A. Modernelli, S. Bettuzzi, F. Rizzi, Roles of autophagy induced by natural compounds in prostate cancer, Biomed Res Int 2015 (2015) 121826. 10.1155/2015/121826.

[85] M.A. Rahman, M.R. Rahman, T. Zaman, M.S. Uddin, R. Islam, M.M. Abdel-Daim, H. Rhim, Emerging Potential of Naturally Occurring Autophagy Modulators Against Neurodegeneration, Curr Pharm Design 26 (2020) 772-779. 10.2174/1381612826666200107142541.

[86] M.S. Uddin, A. Al Abdullah, M.A. Rahman, M.T. Kabir, S. Alkahtani, I.S. Alanazi, A. Perveen, G.M. Ashraf, M.N. Bin-Jumah, M.M. Abdel-Daim, Exploring the Promise of Flavonoids to Combat Neuropathic Pain: From Molecular Mechanisms to Therapeutic Implications, Front Neurosci-Switz 14 (2020). ARTN 478

10.3389/fnins.2020.00478.

[87] B.Y. Law, W.K. Chan, S.W. Xu, J.R. Wang, L.P. Bai, L. Liu, V.K. Wong, Natural small-molecule enhancers of autophagy induce autophagic cell death in apoptosis-defective cells, Sci Rep 4 (2014) 5510. 10.1038/srep05510.

[88] L.S. Li, Y.L. Lu, J. Nie, Y.Y. Xu, W. Zhang, W.J. Yang, Q.H. Gong, Y.F. Lu, Y. Lu, J.S. Shi, Dendrobium nobile Lindl alkaloid, a novel autophagy inducer, protects against axonal degeneration induced by Abeta25-35 in hippocampus neurons in vitro, CNS Neurosci Ther 23 (2017) 329-340. 10.1111/cns.12678.

[89] Y. Chen, Y.L. Chen, Y.B. Liang, H.D. Chen, X.Y. Ji, M. Huang, Berberine mitigates cognitive decline in an Alzheimer's Disease Mouse Model by targeting both tau hyperphosphorylation and autophagic clearance, Biomed Pharmacother 121 (2020). ARTN 109670

10.1016/j.biopha.2019.109670.

[90] Q.C. Zhang, H.M. Bian, L.W. Guo, H.X. Zhu, Pharmacologic preconditioning with berberine attenuating ischemia-induced apoptosis and promoting autophagy in neuron, Am J Transl Res 8 (2016) 1197-1207.

[91] N.N. Yuan, C.Z. Cai, M.Y. Wu, H.X. Su, M. Li, J.H. Lu, Neuroprotective effects of berberine in animal models of Alzheimer's disease: a systematic review of pre-clinical studies, Bmc Complem Altern M 19 (2019). ARTN 109

10.1186/s12906-019-2510-z.

[92] L.L. Chen, J.X. Song, J.H. Lu, Z.W. Yuan, L.F. Liu, S.S.K. Durairajan, M. Li, Corynoxine, a Natural Autophagy Enhancer, Promotes the Clearance of Alpha-Synuclein via Akt/mTOR Pathway, J Neuroimmune Pharm 9 (2014) 380-387. 10.1007/s11481-014-9528-2.

[93] Q. Zeng, W. Siu, L. Li, Y. Jin, S. Liang, M. Cao, M. Ma, Z. Wu, Autophagy in Alzheimer's disease and promising modulatory effects of herbal medicine, Exp Gerontol 119 (2019) 100-110. 10.1016/j.exger.2019.01.027.

[94] Y.Y. Fan, N. Wang, A. Rocchi, W.R. Zhang, R. Vassar, Y.F. Zhou, C.C. He, Identification of natural products with neuronal and metabolic benefits through autophagy induction, Autophagy 13 (2017) 41-56. 10.1080/15548627.2016.1240855. 
[95] X.D. Guo, J.L. Lv, J. Lu, L. Fan, X. Huang, L.H. Hu, J.Y. Wang, X. Shen, Protopanaxadiol derivative DDPU improves behavior and cognitive deficit in AD mice involving regulation of both ER stress and autophagy, Neuropharmacology 130 (2018) 77-91. 10.1016/j.neuropharm.2017.11.033.

[96] M. Huang, X. Jiang, Y.B. Liang, Q. Liu, S.Y. Chen, Y. Guo, Berberine improves cognitive impairment by promoting autophagic clearance and inhibiting production of beta-amyloid in APP/tau/PS1 mouse model of Alzheimer's disease, Exp Gerontol 91 (2017) 25-33. 10.1016/j.exger.2017.02.004.

[97] X. Song, B. Liu, L. Cui, B. Zhou, W. Liu, F. Xu, T. Hayashi, S. Hattori, Y. Ushiki-Kaku, S.I. Tashiro, T. Ikejima, Silibinin ameliorates anxiety/depression-like behaviors in amyloid beta-treated rats by upregulating BDNF/TrkB pathway and attenuating autophagy in hippocampus, Physiol Behav 179 (2017) 487-493. 10.1016/j.physbeh.2017.07.023.

[98] X.B. Meng, Y. Luo, T. Liang, M.X. Wang, J.Y. Zhao, G.B. Sun, X.B. Sun, Gypenoside XVII Enhances Lysosome Biogenesis and Autophagy Flux and Accelerates Autophagic Clearance of Amyloid-beta through TFEB Activation, J Alzheimers Dis 52 (2016) 1135-1150. 10.3233/Jad-160096.

[99] X. Liu, W.L. Hao, Y.R. Qin, Y. Decker, X. Wang, M. Burkart, K. Schotz, M.D. Menger, K. Fassbender, Y. Liu, Long-term treatment with Ginkgo biloba extract EGb 761 improves symptoms and pathology in a transgenic mouse model of Alzheimer's disease, Brain Behav Immun 46 (2015) 121-131. 10.1016/j.bbi.2015.01.011.

[100] H. Zhao, Z.C. Wang, K.F. Wang, X.Y. Chen, A beta peptide secretion is reduced by Radix Polygalaeinduced autophagy via activation of the AMPK/mTOR pathway, Mol Med Rep 12 (2015) 2771-2776. 10.3892/mmr.2015.3781.

[101] B.S. Du, Z.Y. Zhang, N. Li, Madecassoside prevents A beta(25-35)-induced inflammatory responses and autophagy in neuronal cells through the class III PI3K/Beclin-1/Bcl-2 pathway, Int Immunopharmacol 20 (2014) 221-228. 10.1016/j.intimp.2014.02.036.

[102] S.M. Huang, S.Y. Tsai, J.A. Lin, C.H. Wu, G.C. Yen, Cytoprotective effects of hesperetin and hesperidin against amyloid beta-induced impairment of glucose transport through downregulation of neuronal autophagy, Mol Nutr Food Res 56 (2012) 601-609. 10.1002/mnfr.201100682.

[103] Y. Zhu, J. Wang, Wogonin increases beta-amyloid clearance and inhibits tau phosphorylation via inhibition of mammalian target of rapamycin: potential drug to treat Alzheimer's disease, Neurol Sci 36 (2015) 1181-1188. 10.1007/s10072-015-2070-z.

[104] C. Wang, X. Zhang, Z. Teng, T. Zhang, Y. Li, Downregulation of PI3K/Akt/mTOR signaling pathway in curcumin-induced autophagy in APP/PS1 double transgenic mice, Eur J Pharmacol 740 (2014) 312-320. 10.1016/j.ejphar.2014.06.051.

[105] V. Vingtdeux, L. Giliberto, H. Zhao, P. Chandakkar, Q. Wu, J.E. Simon, E.M. Janle, J. Lobo, M.G. Ferruzzi, P. Davies, P. Marambaud, AMP-activated protein kinase signaling activation by resveratrol modulates amyloid-beta peptide metabolism, J Biol Chem 285 (2010) 9100-9113. 10.1074/jbc.M109.060061.

[106] M.A. Rahman, N.H. Kim, S.H. Kim, S.M. Oh, S.O. Huh, Antiproliferative and cytotoxic effects of resveratrol in mitochondria-mediated apoptosis in rat b103 neuroblastoma cells, Korean J Physiol Pharmacol 16 (2012) 321-326. 10.4196/kjpp.2012.16.5.321.

[107] M.S. Uddin, A.A. Mamun, M. Jakaria, S. Thangapandiyan, J. Ahmad, M.A. Rahman, B. Mathew, M.M. Abdel-Daim, L. Aleya, Emerging promise of sulforaphane-mediated Nrf2 signaling cascade against neurological disorders, Sci Total Environ (2019) 135624. 10.1016/j.scitotenv.2019.135624.

[108] J. Liu, H. Su, Q.M. Qu, Carnosic Acid Prevents Beta-Amyloid-Induced Injury in Human Neuroblastoma SH-SY5Y Cells via the Induction of Autophagy, Neurochem Res 41 (2016) 2311-2323. 10.1007/s11064-0161945-6. 
[109] Y.Q. Zeng, J. Zhang, Y.G. Zhu, J. Zhang, H. Shen, J.P. Lu, X.D. Pan, N. Lin, X.M. Dai, M. Zhou, X.C. Chen, Tripchlorolide improves cognitive deficits by reducing amyloid beta and upregulating synapse-related proteins in a transgenic model of Alzheimer's Disease, J Neurochem 133 (2015) 38-52. 10.1111/jnc.13056. [110] M.Z. Deng, L.P. Huang, B.L. Ning, N.B. Wang, Q.X. Zhang, C.X. Zhu, Y.Q. Fang, beta-asarone improves learning and memory and reduces Acetyl Cholinesterase and Beta-amyloid 42 levels in APP/PS1 transgenic mice by regulating Beclin-1-dependent autophagy, Brain Res 1652 (2016) 188-194. 10.1016/j.brainres.2016.10.008.

[111] N. Ryoo, M.A. Rahman, H. Hwang, S.K. Ko, S.Y. Nah, H.C. Kim, H. Rhim, Ginsenoside Rk1 is a novel inhibitor of NMDA receptors in cultured rat hippocampal neurons, J Ginseng Res 44 (2020) 490-495. 10.1016/j.jgr.2019.04.002.

[112] X. Lin, S.J. Zhang, R.B. Huang, L. Wei, S.M. Tan, C.H. Liang, S.J. Lv, Y.X. Chen, S. Liang, Y.C. Tian, Z.P. Lu, Q.F. Huang, Protective effect of madecassoside against cognitive impairment induced by D-galactose in mice, Pharmacol Biochem Be 124 (2014) 434-442. 10.1016/j.pbb.2014.07.014.

[113] Y. Cho, H. Hwang, M.A. Rahman, C. Chung, H. Rhim, Elevated O-GlcNAcylation induces an antidepressant-like phenotype and decreased inhibitory transmission in medial prefrontal cortex, Sci Rep 10 (2020) 6924. 10.1038/s41598-020-63819-6.

[114] M.A. Rahman, H. Hwang, Y. Cho, H. Rhim, Modulation of O-GlcNAcylation Regulates Autophagy in Cortical Astrocytes, Oxid Med Cell Longev 2019 (2019) 6279313. 10.1155/2019/6279313.

[115] H.J. Kim, D.J. Kim, E.J. Shin, B.H. Lee, S.H. Choi, S.H. Hwang, H. Rhim, I.H. Cho, H.C. Kim, S.Y. Nah, Effects of gintonin-enriched fraction on hippocampal cell proliferation in wild-type mice and an APPswe/PSEN-1 double Tg mouse model of Alzheimer's disease, Neurochem Int 101 (2016) 56-65. 10.1016/j.neuint.2016.10.006.

[116] J. Moon, S.H. Choi, J.Y. Shim, H.J. Park, M.J. Oh, M. Kim, S.Y. Nah, Gintonin Administration is Safe and Potentially Beneficial in Cognitively Impaired Elderly, Alz Dis Assoc Dis 32 (2018) 85-87. 10.1097/Wad.0000000000000213.

[117] B.A.Q. Gomes, J.P.B. Silva, C.F.R. Romeiro, S.M. dos Santos, C.A. Rodrigues, P.R. Goncalves, J.T. Sakai, P.F.S. Mendes, E.L.P. Varela, M.C. Monteiro, Neuroprotective Mechanisms of Resveratrol in Alzheimer's Disease: Role of SIRT1, Oxidative Medicine and Cellular Longevity (2018). Artn 8152373

$10.1155 / 2018 / 8152373$.

[118] S.D. Rege, T. Geetha, G.D. Griffin, T.L. Broderick, J.R. Babu, Neuroprotective effects of resveratrol in Alzheimer disease pathology, Front Aging Neurosci 6 (2014). UNSP 218

10.3389/fnagi.2014.00218.

[119] J. Song, N. Li, Y. Xia, Z. Gao, S.F. Zou, L. Kong, Y.J. Yao, Y.N. Jiao, Y.H. Yan, S.H. Li, Z.Y. Tao, G. Lian, J.X. Yang, T.G. Kang, Arctigenin Treatment Protects against Brain Damage through an Anti-Inflammatory and Anti-Apoptotic Mechanism after Needle Insertion, Front Pharmacol 7 (2016). ARTN 182

10.3389/fphar.2016.00182.

[120] M. Rossi, E.R. Munarriz, S. Bartesaghi, M. Milanese, D. Dinsdale, M.A. Guerra-Martin, E.T. Bampton, P. Glynn, G. Bonanno, R.A. Knight, P. Nicotera, G. Melino, Desmethylclomipramine induces the accumulation of autophagy markers by blocking autophagic flux, J Cell Sci 122 (2009) 3330-3339. 10.1242/jcs.048181.

[121] E. Donohue, A. Tovey, A.W. Vogl, S. Arns, E. Sternberg, R.N. Young, M. Roberge, Inhibition of autophagosome formation by the benzoporphyrin derivative verteporfin, J Biol Chem 286 (2011) 72907300. 10.1074/jbc.M110.139915. 
[122] S. Bandyopadhyay, J. Ni, A. Ruggiero, K. Walshe, M.S. Rogers, N. Chattopadhyay, M.A. Glicksman, J.T. Rogers, A high-throughput drug screen targeted to the 5 'untranslated region of Alzheimer amyloid precursor protein mRNA, J Biomol Screen 11 (2006) 469-480. 10.1177/1087057106287271.

[123] L.J. Morse, S.M. Payton, G.D. Cuny, J.T. Rogers, FDA-preapproved drugs targeted to the translational regulation and processing of the amyloid precursor protein, J Mol Neurosci 24 (2004) 129-136. 10.1385/JMN:24:1:129.

[124] S. Payton, C.M. Cahill, J.D. Randall, S.R. Gullans, J.T. Rogers, Drug discovery targeted to the Alzheimer's APP mRNA 5'-untranslated region: the action of paroxetine and dimercaptopropanol, J Mol Neurosci 20 (2003) 267-275. 10.1385/JMN:20:3:267. 